\title{
Hacia México 68. Pedro Ramírez Vázquez y el proyecto olímpico*
}

\author{
Ariel Rodríguez Kuri
}

\section{PRESENTACIÓN}

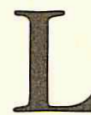

os juegos olímpicos modernos son la actualización de ciertos valores de antiguo régimen en los ambientes profundamente plebeyos de las sociedades de masas del siglo Xx. Se puede decir más: la idea original de Pierre de Coubertin asumía que el ejercicio físico y la competencia deportiva desinteresada deberían de convertirse en uno de los elementos sustentadores -educativa, moral, políticamente hablando- de la III República francesa. En el origen de los juegos modernos hay de todo menos anacronismo o extravagancia. ${ }^{1}$

* La investigación documental y hemerográfica para este trabajo fue financiada por el Consejo Nacional de Ciencia y Tecnología. Pude escribir el artículo gracias a la hospitalidad del Center for U.S.-Mexican Studies de la Universidad de California en San Diego, donde realicé una estancia sabática en el año lectivo 2001-2002. Recibí comentarios de Eric Zolov a una versión preliminar del texto. El eminente y generoso Eric van Young leyó una versión más completa, y advirtió algunos puntos clave. Mis colegas Theresa A. Velcamp, Mark Mairot, Antonio Ibarra y Daniela Traffano se afanaron en ayudarme en cada versión del trabajo. Consuelo Córdoba dibujó el plano. A todos, mi agradecimiento.

${ }^{1}$ Soy deudor en esta caracterización de un estudio a la fecha insuperado, y cuya importancia va más
Educación pública y republicanismo, laicismo y nacionalismo son ideas centrales en la fundación moderna del olimpismo. Los cuatro son asimismo temas y problemas esenciales en la reconstrucción del Estado y la sociedad después de la revolución. Los cuatro son, por lo tanto, temas de la historia política y de la historia de la cultura política mexicana en el siglo Xx. El olimpismo moderno -es decir, una ideología, una organización y una políti$\mathrm{ca}^{2}{ }^{2}$ y la imaginación política y cultural de la revolución se reunieron con motivo de los juegos olímpicos de 1968. Aquella comunión, en una década legendaria, nos deja todavía perplejos. ${ }^{3}$ No puedo disipar esa perplejidad, pero en cambio quiero iniciar una discusión sobre la historia de la olimpiada mexicana donde asumo -pero no abordo aquí- la existencia de grandes temas que apenas entrevemos historiográficamente: la dinámica cada

allá del propio Coubertin y dei olimpismo moderno, MacAloon, Great, 1981.

${ }^{2}$ Uno de los muy pocos trabajos que han tracado de entender, conceptual e históricamente, el olimpismo moderno es el de Hoberman, "Toward", 1995, pp. 1-37. Otro trabajo útil y sugerente (aunque un tanto esquemático) es el de Roche, Mega-Events, 2000.

${ }^{3}$ Un enfoque fundamental sobre la década, y del cual también soy y seré deudor, es Marwik, Sixties, 1998. 


\section{SECUENCIA}

Secuencia (2003), 56, mayo-agosto, 35-74

ISSN: 0186-0348, ISSN electrónico: 2395-8464

DOI: http://dx.doi.org/10.18234/secuencia.v0i56.812

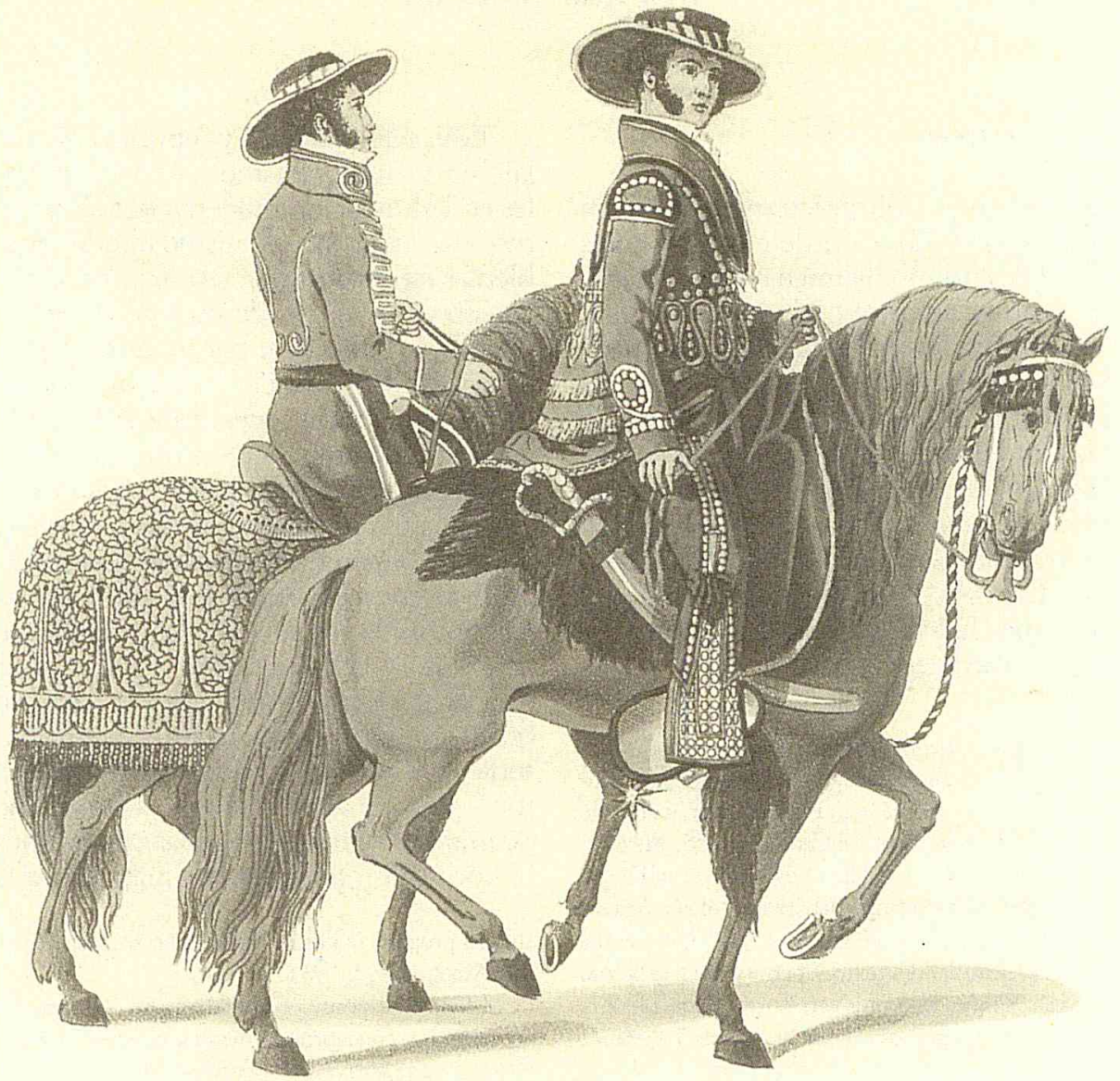

William Bullock Jr., Mexican gentlemen. 
vez más álgida de disidencia/negociación de los grupos populares y las clases medias con el gobierno nacional y los gobiernos locales a partir de 1958; la aparición de fisuras y conflictos en la elite del oficialismo, cuya unidad y homogeneidad política -me temo-casi siempre han sido sobrevalorados, y, por supuesto, el origen, desarrollo y desenlace del movimiento estudiantil de $1968 .^{4}$

Trabajo en la escritura de una historia política de la olimpiada de 1968. En ese camino, quiero plantear en este artículo dos problemas que me parecen fundamentales. En un primer apartado procuro reconstruir lo que podríamos llamar los trabajos y los días de Pedro Ramírez Vázquez como una de las figuras centrales en la experiencia olímpica mexicana, y al mismo tiempo, identifico algunos rasgos en la formación de un discurso olímpico desde México. Sugiero en todo caso que la llegada de Ramírez Vázquez a la presidencia del comité organizador de los juegos se convirtió en la condición de posibilidad para una apropiación y recreación del universo axiológico del olimpismo en un tono mexicano.

En el segundo apartado de este texto pondero la naturaleza de la olimpiada de 1968 en cuanto a su relación con la ciudad de México. Ahí propongo que si algo caracterizó a la organización de los juegos fue el inocultable sentido pragmático de los organizadores, que adaptaron los juegos a la ciudad, y no al revés. Argumento que los dispositivos técnicos e ideológicos

${ }^{4}$ Para acercarnos a la década de 1960 pueden ser de utilidad los siguientes estudios: Hernández, Formación, 1991, pp. 110 y ss.; Loaeza, Clases, 1988; Koslow, "Mexican", 1969; Carr, Izquierda, 1996, caps. vi y vII; Zermeño, México, 1978. para esa operación (la idea de urbanismo vivo y el compromiso político de una olimpiada "barata") serían las aportaciones locales más originales a la ya dilatada saga olímpica de la última centuria.

La ciudad de México obtuvo la sede de los XIX Juegos Olímpicos de la era moderna en la reunión del Comité Olímpico Internacional (en adelante COI) celebrada en Baden-Baden, República Federal Alemana, en octubre de 1963. En aquella reunión la ciudad de México recibió 30 votos, Detroit 16, Lyon doce y Buenos Aires dos. No es un dato menor que la ciudad capital haya triunfado en la primera ronda. La naturaleza de los factores internacionales y nacionales que obraron en favor de la candidatura mexicana no serán discutidos en este artículo, pero al menos deben ser enunciados para una mejor comprensión de la no poco sorprendente victoria de la candidatura mexicana. He sugerido que el ritmo del conflicto bipolar en la primera mitad de la década de 1960, las amenazas al monopolio deportivo que ejercía (y ejerce) el Comité Olímpico Internacional de parte de algunos países no alineados y, last but no least, la escalada de costos que la sede de Tokio supuso para toda la experiencia olímpica futura, seguramente contribuyeron a que la candidatura mexicana recibiera un fuerte apoyo de Avery Brundage, presidente del CoI desde 1952. A estos factores, de orden externo, deben sumarse la estabilidad (quizá más aparente que real) del modelo político mexicano y un desempeño favorable de la economía nacional. ${ }^{5}$

${ }^{5}$ Algunas razones por las cuales la ciudad de México triunfó en Baden-Baden las discuto en Rodríguez Kuri, “Otro”, 1998. Véase asimismo Seen, Power; 1999, pp. 79-80, donde se presentan los desafíos 
LOS HOMBRES Y EL PROYECTO

DE LOS JUEGOS MEXICANOS

Pedro Ramírez Vázquez recordaría siempre el consejo de su maestro José Luis Cuevas en la Escuela Nacional de Arquitectura: "el urbanismo sin el poder es sólo un bobby". ${ }^{6}$ La trayectoria profesional y pública de Ramírez Vázquez muestra que aquella frase la convirtió en una verdadera certeza, en una suerte de programa desde el cual fue posible combinar los saberes del arquitecto, del urbanista, del organizador y del hombre público. Para un hombre que obtuvo su título de arquitecto en 1944 con una tesis que él mismo juzga como la primera que utilizó explícitamente un enfoque urbanístico en la Escuela Nacional de Arquitectura, ${ }^{7}$ la presidencia del comité organizador de los juegos olímpicos de la ciudad de México representó una oportunidad privilegiada para sintetizar sus experiencias y convicciones intelectuales, artísticas, técnicas y políticas.

Ramírez Vázquez fue nombrado presidente del comité organizador por Gustavo Díaz Ordaz el 16 de julio de 1966. Sustituyó en el cargo al ex presidente de la república Adolfo López Mateos, quien para ese entonces se encontraba enfermo. Hasta ese momento Ramírez Vázquez era vicepresidente de construcción de obras del comité organizador. De hecho, en el primer organigrama, Ramírez Vázquez era el cuarto en la jerarquía, después de López Mateos (presidente), José de Jesús Clark

que las naciones recientemente independizadas y el surgimiento de un bloque de países no alineados significaron para el Comité Olímpico Internacional.

${ }^{6}$ Aguilar, Ramírez Vázquez, 1995, p. 59.

${ }^{7}$ Ibid., pp. 56-57.
Flores (presidente ejecutivo) y Agustín Legorreta (vicepresidente de finanzas). Por qué recayó en él tal nombramiento no es una cuestión menor en la historia de los juegos mexicanos. Ramírez Vázquez ha reconocido más de una vez que su contacto con el ambiente olímpico y el deporte en general era muy limitado. Nunca había asistido a una olimpiada. Tampoco había practicado un deporte de forma sistemática; a lo más - dice- había jugado futbol, de manera informal, con sus compañeros en la facultad, allá a principios de 1940, o veía los partidos en la televisión, en tiempos más recientes. ${ }^{\mathrm{s}}$

Desde un punto de vista, entonces, Ramírez Vázquez era un verdadero outsider en el ambiente olímpico local e internacional. Este es un dato que nos ayudará a descubrir las disyuntivas que enfrentaba la organización de los juegos mexicanos hacia mediados de 1966. El nombramiento de Ramírez Vázquez fue hecho directa e inmediatamente por el presidente Díaz Ordaz el mismo día en que López Mateos renunció. Sin embargo, al menos un periódico notó que en el boletín de prensa del comité organizador López Mateos había informado a Díaz Ordaz de "la amplia colaboración que le han brindado todos los miembros del comité [...] especialmente el ingeniero José de Jesús Clark Flores". 9 Tal vez López

${ }^{8}$ Ramírez Vázquez repite este argumento en varios lugares. Por ejemplo Iannini, Charlas, 1988, pp. 97-98, y Ramírez Vázquez,1989, p. 143.

9 Rivera, "Diseño", 1999. Entrevista de Ariel Rodríguez Kuri a Pedro Ramírez Vázquez (en adelante PRV), realizada el 24 de septiembre de 1999. Recortes de periódicos Excélsior y Novedades, 16 de julio de 1966 en Archivo General de la Nación (en adelante AGN), fondo Investigaciones Políticas y Sociales (en adelante FIPS), caja 435. 
Mateos quiso heredar el cargo a este último, pero hay otro dato igualmente importante: en los círculos del gobierno era bien sabido que Clark Flores era el hombre de Avery Brundage ( presidente del COI) en México. ${ }^{10}$

Clark Flores era miembro del CoI desde 1952. Ese año viajó a Helsinki y escribió una memoria de la participación mexicana en aquellos juegos olímpicos. Lo notable del documento es que prestó una atención pormenorizada no tanto a los resultados deportivos como a las formas y mecanismos de organización de unos juegos olímpicos: "Helsinki dio al deporte mexicano algo más valioso que triunfos utilitarios: [dio] la medida exacta de cómo puede emprenderse el camino del éxito", escribió en 1952. Para Clark "el camino del éxito" significaba la obtención de la sede olímpica. Existe evidencia de que desde 1948 el gobierno mexicano mostraba interés en obtener la sede, aunque al parecer no formalizó la solicitud aquel año. Pero en 1955 solicitó formalmente al cor la sede para los juegos de 1960, y formó un comité de invitación donde Clark figuraba como segundo vicepresidente. Juzgo yo que Clark Flores era el enlace más importante entre el ambiente olímpico mexicano y el COI. Su papel en 1962 y 1963 fue relevante en la promoción de la candidatura mexicana y en la obtención de la sede. Más aún, Clark Flores era amigo personal de Brundage. ${ }^{11}$

${ }^{10}$ Casellas, México, 1992, pp. 15-23.

${ }^{11}$ Para la fecha de afiliación de Clark en el COI, Krotee, "Organizational", 1988, p. 131. El informe de 1952 se encuentra en Clark e Isse, Juegos, [1952]. Respecto al interés por la sede olímpica, véase el trámite que en 1948 hizo un diplomático mexicano ante un miembro del cor en González, Memorias,
Pero algo más se adeudaba a Clark Flores: el manejo decidido de lo que podría considerarse la primera crisis de importancia en la organización de los juegos mexicanos. En diciembre de 1964 y enero de 1965 Clark Flores recibió dos cartas cuyo contenido, bien vistas las cosas, constituía una verdadera bomba política. La primera misiva provenía de la Unión Atlética Amateur de Estados Unidos. La segunda carta estaba firmada por Kenneth L. Wilson, presidente del Comité Olímpico de Estados Unidos. Ambas cartas coinciden en un punto: la necesidad de modificar el calendario de los juegos mexicanos -desde entonces programados para octubre- ya fuese para abril, septiembre o noviembre de 1968. Si bien en ambos casos se habla de la necesidad de aumentar las posibilidades de que los turistas estadunidenses viajen a México, también se descubre otra razón: aligerar la agenda de las televisoras de Estados Unidos, que para octubre de 1968 tenían compromisos tan importantes como la serie mundial, el futbol americano y la cobertura de las campañas para las elecciones presidenciales que se celebrarían en noviembre. ${ }^{12}$

1993, p. 107. La solicitud para la sede de 1960 consta en tres documentos muy importantes: el "Acuerdo del Departamento del Distrito Federal", 4 de mayo de 1955; el mensaje de Ernesto P. Uruchurtu al COI, 23 de mayo de 1955 y el acuerdo del Departamento del Distrito Federal para integrar el comité de invitación, 23 de mayo de 1955; los tres documentos fueron compilados en Ciudad, s. a. [1955] s. p. La amistad de Brundage y Clark es comentada por Guttmann, Games, 1984, p. 239.

${ }^{12}$ De Clark Flores a K. S. Duncan (Asociación Olímpica de la Gran Bretaña), 23 de diciembre de 1964; de Keneth Wilson a Clark, 7 de enero de 1965, ambas en Archivo del Comité Organizador de los 
Clark respondió a las solicitudes de forma audaz. Primeramente corrigió a Wilson, quien pensaba que el 12 de octubre había sido escogido como la fecha inaugural de los juegos por ser el Día de la Raza. En absoluto, escribió Clark: el día fue seleccionado porque representaba "el sábado más indicado" de octubre desde el punto de vista meteorológico (y no sé si hay algo de ironía en la respuesta). Clark recordó además a los estadunidenses que los juegos de Tokio "comenzaron precisamente el día 10 de octubre, y los japoneses no recibieron ninguna reclamación por ese motivo". Ahora bien, en las condiciones climatológicas de la ciudad de México, sigue Clark, el mes más indicado sería abril. Pero abril representaba un problema serio para los países situados al norte del paralelo 30 -Estados Unidos, Canadá, y muchos de los países europeos-, ya que los inviernos severos en esas latitudes disminuirían el tiempo disponible para los entrenamientos al aire libre de los atletas. Noviembre, a su vez, estaba descartado desde el principio por las altas probabilidades de lluvia. Clark sabía dramatizar: México -le dice a Wilson- no cuenta con "atletas sobresalientes"; en cambio, "lo mejor que puede ofrecer a todos ustedes es su alegría y el sol de la región más transparente del aire, y esto, mi querido amigo, le ruego que no nos lo quite, obligándonos a celebrar unos juegos pasados por agua". ${ }^{13}$

Juegos Olímpicos (en adelante ACojo), caja 386, exp. 460 y caja 386, exp. 453. Véase Rodríguez Kuri, "Otro", 1998, donde discuto con más detalle los argumentos estadunidenses, mexicanos y europeos sobre el calendario de 1968.

13. De Clark a Wilson, 30 de enero de 1965, en ACOJO, caja 386, exp. 453. Cursivas mías.
Clark se cuidó de enfrentar solo las demandas de los dirigentes deportivos estadunidenses. Hacia febrero de 1965 sabía con qué elementos contaba para resistir la presión. Una copia de las cartas fue enviada a los comités olímpicos nacionales (o al menos a los más importantes). La respuesta de K. S. Duncan, de la Asociación Olímpica Británica, es un buen ejemplo de lo que esperaba Clark. Duncan empieza por reconocer que el asunto del calendario de los juegos debe ser tratado solamente entre el Comité Olímpico Internacional y el comité organizador. Ahora bien, ya que se le ha consultado, descarta de inmediato el mes de abril, pues una fecha tan temprana en el año creaba muchas dificultades para los británicos (seguramente relacionadas con el calendario de preparación de los atletas). La última semana de agosto y la primera de septiembre no sonaban mal, pero el asunto de las lluvias le preocupaba. En cambio octubre, sin lluvias, aparece como la mejor opción. Ahora bien, sea cual fuere la decisión del comité organizador sobre el calendario, termina Duncan, los ingleses enviarían una delegación a México. Los japoneses, los italianos, los franceses y los soviéticos anduvieron por el mismo tenor. ${ }^{14}$

${ }^{14}$ De K. S. Duncan al comité organizador, 19 de enero de 1965 en ACOJO, caja 386, exp. 460; de Tsuneyashi Takeda (del Comité Olímpico Japonés) al comité organizador, 19 de febrero de 1965 en ibid., caja 386, exp 479; de Giulio Oresti (del Comité Olímpico Italiano), al comité organizador, 12 de febrero de 1965, en ibid., caja 386, exp. 477; del Comité Olímpico de la uRss al comité organizador, 24 de diciembre de 1964 en ibid., caja 387, exp. 529; de Armand Massard (presidente del Comité Olímpico Francés), al comité organizador, 8 de febrero de 1965 en ibid., caja 386, exp. 458. 
La solicitud de los organismos olímpicos estadunidenses debe ser entendida en su justa dimensión, como debe ser entendida la respuesta de Clark Flores. No es difícil inferir que se trató, abiertamente, de un chantaje, dada la importancia política de Estados Unidos para México, la importancia de ese país como competidor olímpico y la suculenta zanahoria de los millones de dólares por derechos de televisión.

Clark entendió el mensaje, y abrió el juego al resto de los socios olímpicos. La posibilidad de que Clark estuviese actuando de acuerdo con Brundage al solicitar la opinión de los comités olímpicos nacionales es muy alta. Sea lo que sea, a final de cuentas no hubo cambio de calendario, y los organizadores obtuvieron unos 20000000 de dólares por los derechos de televisión. Pero, sobre todo, Clark Flores contribuyó a mantener el control local de los juegos.

Sin embargo, para mediados de 1966 la estrella política de Clark Flores estaba en caída libre. Ya en mayo de ese año, un informe dirigido a Fernando Gutiérrez Barrios, en ese entonces responsable de la Dirección Federal de Seguridad (ésta, el ala operativa y más temida de la policía política mexicana), hacía un seguimiento pormenorizado de la empresa Constructora Chapultepec S. A., desde su fundación en 1948. Del reporte de esa dependencia se desprende claramente que Clark Flores - uno de los fundadores de la empresa- se había convertido hacia 1958 en el principal accionista de la constructora (con 60\% de los títulos) y era el presidente de su consejo de administración. Conocida la discrecionalidad con la que actuaban las agencias de espionaje y represión política en México, no es de sorprender la existencia de un informe como éste. ${ }^{15}$

Pero algo se estaba cocinando. El 21 de octubre de 1966, Brundage, de visita en México, declaró a la prensa que había felicitado al presidente Díaz Ordaz "por el magnífico equipo que componen el arquitecto Pedro Ramírez Vázquez y el general Clark Flores"; con estos dos personajes trabajando juntos, "los juegos llegarán a una feliz realización". Las zalameras declaraciones de Brundage fueron poco eficaces y más bien sintomáticas. Apenas unos días después, y por instrucciones directas de Díaz Ordaz, Clark Flores tuvo que renunciar, en la misma noche, a su cargo en el comité organizador, a la presidencia del Comité Olímpico Mexicano y a la presidencia de la Confederación Deportiva Mexicana. De hecho, Clark sólo mantuvo su posición -que ciertamente no dependía del gobierno mexicano- como miembro del Comité Olímpico Internacional. ${ }^{16}$

Las derrotas de Clark Flores en julio y octubre de 1966 evidencian algo más: su marginación total de las tareas ejecutivas era el primer paso para una reestructuración completa del comité organizador. A fines de octubre, un decreto de Díaz Ordaz (pero muy probablemente a soli-

${ }^{15}$ De Santiago Peña al titular de la Dirección Federal de Seguridad, 26 de mayo de 1966, en AGN, FIPS, caja 2928, s/e.

${ }^{16}$ Las declaraciones de Brundage en Recortes de prensa, El Heraldo de México, 22 de octubre de 1966 en ACOJO, caja 404. El encargado de pedirle la renuncia a Clark de sus tres presidencias fue Alejandro Ortega San Vicente; véase su testimonio en "Los juegos de la XIX Olimpiada", 28 de septiembre de 1998, en Documentos de Pedro Ramírez Vázquez (en adelante DPRV). 
citud de Ramírez Vázquez y su equipo) replanteó la estructura del comité. Esste quedó integrado por una sola presidencia, una vicepresidencia, tres vocalías, una secretaría general, una oficialía mayor y siete direcciones. Desaparecieron del nuevo organigrama la separación, un poco inexplicable, entre una "presidencia" y una "presidencia honoraria" y las 18 secciones (correspondientes a cada uno de los deportes olímpicos) que funcionaban hasta ese entonces. De hecho, se simplificó la estructura del comité y se dotó al presidente y a los otros cargos de poderes organizativos y ejecutivos claramente distinguibles. Sospecho que para cualquier efecto práctico, apenas en octubre de 1966 se creó un comité organizador. ${ }^{17}$

Las necesidades de los organizadores eran apremiantes en octubre de 1966. En realidad, al momento de la renuncia de López Mateos, en julio, casi todo estaba por hacerse. Éste había declarado en enero que el mes siguiente se iniciarían "las construcciones olímpicas", aunque los datos que ofreció al respecto no sonaban muy convincentes. ${ }^{18}$ Cuando López Mateos informó a la reunión plenaria del Comité Olímpico Internacional en Roma, en abril, sobre los avances de los trabajos,

${ }^{17}$ Sobre la reestructuración del comité ver el decreto de Díaz Ordaz en Noticiario Olímpico México 68, núm. 32, s. a. en ACojo, caja 390, exp. 2676 (el decreto se publicó en el Diario Oficial el 26 de octubre). Para comentarios de la prensa véase Recorte de prensa, editorial de El Heraldo de México, 29 de octubre de 1966, en ibid., caja 404, exp.

18 "En febrero de 1966 se emprenderán las construcciones olímpicas...", Boletín del Comité Olímpico Internacional, núm. 92, 15 de noviembre de 1965 en ACOJO, caja 393, s. exp. (la fecha del Boletín está desfasada de sus contenidos). tuvo que hablar en futuro: "las instalaciones deportivas necesarias serán construidas por el gobierno mexicano", dijo. ${ }^{19}$

Las críticas al retraso en la construcción de la obra olímpica y al avance muy lento de otros preparativos arreciaban en la prensa internacional. Un periódico de Arizona especulaba en marzo de 1966 sobre la posibilidad de que los juegos se reasignaran a Los Ángeles, pues esa ciudad "tiene ya las instalaciones necesarias", y en cambio en México "van muy atrasadas" las obras olímpicas. The Washington Post de plano se regodeaba en las penurias aztecas: si las cosas siguen como van, "los nadadores saltarán dentro del lago con los canoístas, los caballos empezarán a correr alrededor del velódromo de los ciclistas y los gimnastas empezarán a hacer el salto de altura en la barra". Tan tarde como en enero de 1967 el San Francisco Chronicle recordaba a sus lectores que la opción de Detroit - una de las ciudades que perdió la nominación frente a la de México- estaba viva. El ambiente internacional en relación con la olimpiada mexicana era poco confortable, por no decir adverso. Antes de la crisis del primer semestre de 1966, Brundage mismo se sintió obligado a hacer declaraciones fuertes y un poco en solitario en apoyo a los mexicanos. ${ }^{20}$

${ }^{19}$ Recortes periodísticos: El Dí, La Prensa, El Sol de México, 27 de julio de 1966 en AGN, FIPS, caja 435.

${ }^{20}$ Las críticas y dudas en la prensa extranjera sobre la viabilidad de los juegos de 1968 fueron recopiladas, amplia y detalladamente, por los propios organizadores; véase la memoria oficial de los juegos: México 68, 1969, especialmente vol. 2. Para unas declaraciones de apoyo tempranas de Brundage véase "Mensaje del presidente del Cor", 6 de julio de 1965 en ACOJO, caja 385, exp. 402. 
Un pequeño sector de la prensa mexicana también mostraba preocupación. "Todos los proyectos, confeccionados con el inconfundible estilo de las promesas de un candidato presidencial en gira, se encuentran totalmente realizados... en maqueta", ironizaba Política, en mayo de 1966. Pero la misma revista (quizá la única en disidencia abierta del gobierno de Díaz Ordaz) reconocía, en una entrega posterior, lo grave de la situación:

Desde que México aceptó -acertada o erróneamente-ser anfitrión de los juegos olímpicos de 1968, empeñó su prestigio ante el mundo entero, y es por tanto absolutamente necesario que salga airoso de la prueba. No todo consiste en disponer de un presupuesto de gastos cuantiosos ni de anunciar próximas campañas publicitarias de carácter turístico. Lo esencial es la fortaleza de la estructura que se dé al gran acontecimiento deportivo: hoteles suficientes, buenos medios de comunicación, precios módicos, instalaciones olímpicas impecables. ${ }^{21}$

No fue sino hasta unos seis meses después del nombramiento de Ramírez Vázquez como presidente del comité organizador, y después de su reestructuración, cuando se empezaron a tomar las decisiones fundamentales sobre el arreglo y construcción de la obra olímpica, y probablemente también sobre la creación de una parafernalia y de un cierto ambiente alrededor de la justa deportiva. De hecho, fue entre finales de 1966 y el primer semestre de 1967 cuando se inició la cons-

${ }^{21}$ Política, 1 de mayo y 15 de julio de 1966, pp. 28 y 8 , respectivamente. El mismo tono preocupado y pesimista se nota en el editorial "La olimpiada, una pesada carga", Siempre!, 27 de julio de 1966. trucción de los edificios olímpicos más importantes. ${ }^{22}$

Visto en perspectiva, el nombramiento de Pedro Ramírez Vázquez para presidir el Comité Organizador fue una decisión que presentaba dos grandes ventajas para Díaz Ordaz: por un lado, Ramírez Vázquez era un hombre familiarizado con las prácticas administrativas, de planeamiento y de toma de decisiones del gobierno mexicano, sobre todo en el campo de la obra pública (con la virtud adicional de que conocía los problemas de la ciudad de México). Por otro, don Pedro tenía la ventaja (al menos desde la perspectiva de Díaz Ordaz) de unos lazos más bien débiles con el ambiente y los intereses del Comité Olímpico Internacional.

Hacia mediados de la década de 1960 , Pedro Ramírez Vázquez tenía una trayectoria notable en dos campos ampliamente visibles en la cultura política mexicana: la arquitectura y la administración pública. Sangre de familia tal vez. Dos de sus hermanos mayores tuvieron -antes o al mismo tiempo que Pedro- cargos importantes en el gobierno federal y en el poder judicial: Mariano fue ministro de la Suprema Corte de Justicia de la Nación entre 1954 y 1973 ; Manuel fue secretario del Trabajo entre 1948 y 1952, en el gobierno de Miguel Alemán. Antes de llegar al comité organizador de los juegos olímpicos, Pedro había sido director nacional de CAFPCE, el organismo federal encargado de la construcción de escuelas públicas (1958-1964); director técnico del

22 Para los tiempos previstos de inicio y entrega de los edificios olímpicos más importantes, véase Secretaría de Obras Públicas, Dirección General de Edificios, s. a. en ACOJO, caja 403, exp. 102-111. 


\section{SECUENCIA}

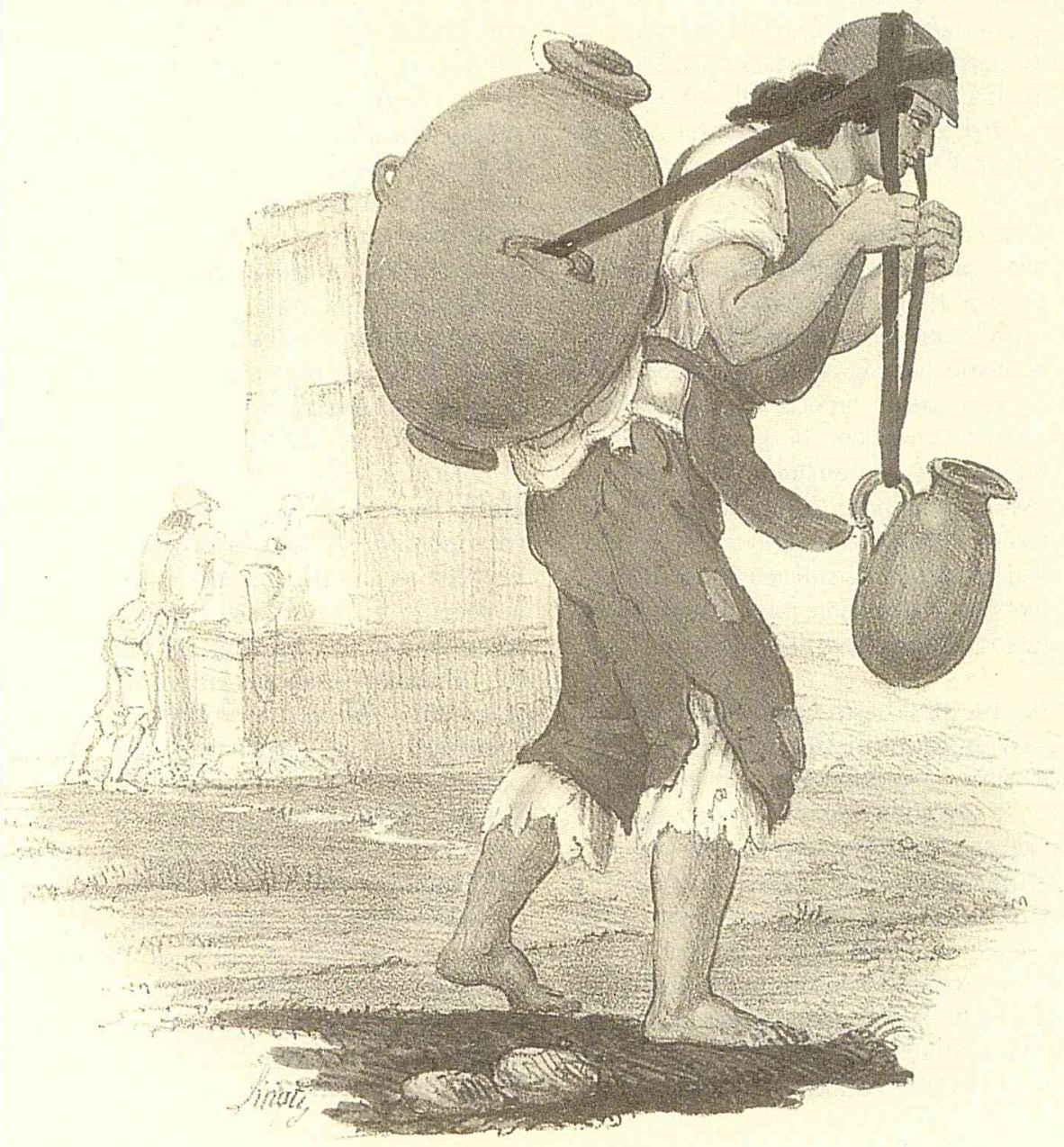

Claudio Linati, Porteur d'ean. 
Centro Regional para la Construcción de Escuelas en América Latina (organismo de la UNESCO), y director de la Unidad Cultural del Bosque de Chapultepec $(1953-1965) .^{23}$

En un sentido más preciso, Ramírez Vázquez era un hombre del sistema. En la campaña electoral de 1958, que lo llevaría a la presidencia de la república, Adolfo López Mateos le encargó un diagnóstico urbanístico de la ciudad de México. En sendos documentos, el futuro presidente del comité organizador de la olimpiada mexicana enunció algunas de las que luego serían las obsesiones de los sociólogos, de los urbanistas, de los demógrafos y de los administradores de las tres décadas subsiguientes: la supresión de los subsidios presupuestales a la capital nacional, la definición de un sistema nacional de planeación económica y demográfica, la creación de incentivos de todo tipo para la desconcentración económica y educativa de la ciudad, etc. ${ }^{24}$ Ramírez Vázquez llegó a pensar que el encargo del candidato López Mateos estaba dirigido a su ulterior nombramiento como jefe del Departamento del Distrito Federal. En 1958, esa figura extraña y emblemática de la política mexicana que se llamó Ernesto P. Uruchurtu se interpuso en el camino. ${ }^{25}$

${ }^{23}$ Camp, Mexican, 1995, pp. 578-579, y Enciclopedia, 1988, vol. xII, pp. 6853-6855. Además "Quiénes dirigen la organización de los juegos de la XIX Olimpiada", datos biográficos, 8 de mayo de 1967 en ACOJO, caja 390, exp. 2676.

${ }^{24}$ Las propuestas de 1958 de Ramírez Vázquez para López Mateos, han sido reproducidas, incompletas, en Aguilar, Ramírez Vázquez, 1995, p. 67.

${ }^{25}$ Ibid., p. 67.
Pero sobre todas las cosas, Pedro Ramírez Vázquez era uno de los arquitectos más importantes de México, con un papel notable en el diseño y construcción de edificios públicos. Joven aún, ideó un diseño modular de aulas escolares con elementos prefabricados para las zonas rurales; con ese modelo se habrían construido unos 35000 módulos en México y el extranjero en el periodo 1958-1964. Antes de su nombramiento en 1966, Ramírez Vázquez había diseñado y construido (solo o en coautoría) la Facultad de Medicina de la Ciudad Universitaria (1950-1952), la Galería de Historia (1959-1960), el Museo de Arte Moderno (1964) y el Museo de Antropología (1963-1964) en la ciudad de México, y el Museo de Ciudad Juárez (1962); la Secretaría del Trabajo (1954) y la Secretaría de Relaciones Exteriores (1965-1968); el Instituto Nacional de Protección a la Infancia (1960); el Estadio Azteca (1963-1966), y los pabellones mexicanos en las expos de Bruselas (1957), Seattle y Nueva York. ${ }^{26}$

Tiene razón uno de sus comentaristas: Ramírez Vázquez "fue el arquitecto de la década de los sesenta". Pero más importante aún, fue el arquitecto de la obra pública dirigida a la educación, la cultura, la salud y el esparcimiento: escuelas, museos, hospitales, estadios, oficinas de gobierno. Estamos ante una arquitectura para usos colectivos, y a veces tumultuarios. Ha sido casi siempre una arquitec-

${ }^{26}$ Como se ve, la obra arquitectónica de Ramírez Vázquez es muy extensa y no puede ser discutida aquí. Para esta brevísima semblanza me apoyo en los siguientes textos: Ramírz Vázquez, 1990; Noelle, Arquitectos, 1989, pp. 131-134, y "Pedro Ramírez Vázquez", 1994, pp. 120-121; Pinoncelly, Pedro Ramírez Vázquez, 2000. 
tura de Estado, sí, pero en lo que éste tiene de público; ha sido a veces una arquitectura para el consumo de masas, sí, pero de masas en busca no sé si de su redención o de su imagen; pienso en esos tres destinos obligados del peregrinaje mexicano de las últimas décadas, y que son, los tres, obra de Ramírez Vázquez: el Museo de Antropología, el Estadio Azteca y la nueva Basílica de Nuestra Señora de Guadalupe (1974-1976). Es una gran arquitectura (por la escala y por los usos intensivos de los edificios) para una sociedad profundamente plebeya. No desconozco la razón que le asiste a Louise Noelle al señalar las dificultades en la valoración de su obra: sus edificaciones son "de reconocida eficiencia funcional aunque no siempre logran una imagen acertada". De ese juicio, sin embargo, Ramírez Vázquez compartiría al menos una parte: "el diseño no es dibujo, es servicio", ha repetido más de una vez. ${ }^{27}$

Su familiaridad con la capital, por una parte, y su nueva posición como encargado de organizar una olimpiada, por la otra, le permitirían a la larga conceptualizar su propia experiencia. Un buen ejemplo de este proceso es la propuesta de Ramírez Vázquez de que la relación entre la ciudad de México y la olimpiada habría sido mediada y organizada por un dispositivo político y técnico que él mismo llamó "urbanismo vivo". ${ }^{28}$ Sugiero que la idea de "urbanismo vivo" es otra cosa que un concepto técnico: expresa la

${ }^{27}$ Pinoncelly, Pedro Ramírez Vázquez, 2000, p. 13; Noelle, "Pedro Ramírez Vázquez", 1994, p. 121; Rivera, "Diseño", 1999, p. 13.

${ }^{28}$ Aguilar, Ramírez Vázquez, 1995, pp. 153-160; Rivera, "Diseño", 1999, p. 23. Entrevista con PRv, 24 de septiembre de 1999. convicción más amplia de que para el éxito de la empresa olímpica era absolutamente necesario reconocer, a tiempo, los límites políticos, financieros y técnicos de tal empresa. El problema de los "límites" es central al entendimiento de los juegos mexicanos, y va de la mano (de hecho se suponen mutuamente) con la creación de una idea más precisa de los juegos.

Para hablar de límites resulta de gran ayuda reconocerse - o no- en un modelo. Veamos. En los 32 años previos a los juegos de 1968 se habían sucedido las ciudades sede de Berlín (1936), Londres (1948), Helsinki (1952), Melbourne (1956), Roma (1960) y Tokio (1964): ¿había, desde el punto de vista de los organizadores mexicanos, un "modelo" a seguir? No conozco ningún documento en que éstos hayan sistematizado las formas logísticas, de comunicación, organizativas, urbanísticas o arquitectónicas de otras sedes olímpicas. Son escasos los juicios por escrito sobre otras experiencias, antes y después de que Ramírez Vázquez fuese nombrado presidente del comité. Quizá no debiera sorprender este hecho: buena parte de la literatura que he revisado para esta investigación se publicó de la década de 1980 en adelante. Lo que se pudo haber consultado en fuentes publicadas era más bien un material limitado: las memorias oficiales de los juegos, sobre todo. Existe testimonio, en cambio, de visitas para consultas y asesorías con los organizadores de los juegos de Tokio, Roma, Melbourne, Helsinki y Londres, y con los miembros más enterados del Comité Olímpico Internacional. ${ }^{29}$

${ }^{29} \mathrm{Al}$ respecto véase Valenzuela, "Instalaciones", 1968 , p. 413. Valenzuela estaba particularmente bien 
A finales de 1965 -es decir antes de la llegada de Ramírez Vázquez a la presidencia del Comité- algunos medios italianos consideraban que los juegos de México estarían inspirados en los de Roma de 1960. Si esto fuera así, ya el hecho de aceptar como modelo la olimpiada romana suponía una elección: que los organizadores mexicanos preferían la experiencia italiana a la de Tokio en 1964, para hablar sólo de los ejemplos cronológicamente más cercanos. Ciertamente, hay elementos que sugieren que la experiencia italiana pudo haber ejercido influencia en los proyectos mexicanos.

En 1965, Marcello Garroni, subsecretario del Comité Olímpico Nacional Italiano, hizo dos viajes a México para asesorar al comité organizador en los proyectos arquitectónicos y de ingeniería de las instalaciones, y en la formación del programa propiamente dicho. Garroni tenía juicios e ideas, y además era muy comunicativo. Por ejemplo, estaba cierto de que los mexicanos intentarán "llevar a cabo los juegos de 1968 [...] a semejanza de los de Roma, con más espíritu humanístico y más calor que los [...] de Tokio". Y fue más allá. Propuso por ejemplo que la carrera de maratón terminara en un Zócalo iluminado, pues "sería un espectáculo muy sugestivo"; además, recomendó que la llama olímpica, "la misma tarde del inicio de las competencias", fuese llevada a la pirámide del Sol en Teotihuacan para escenificar así una ceremonia "de claro sabor azteca, lo que gustaría tanto a los mexicanos como a los turistas" (aunque es difícil saber si a los teotihuacanos). Es

situado para un testimonio como este: era el secretario de Obras Públicas en el gabinete de Gustavo Díaz Ordaz. cierto también que en las estancias de Garroni en la ciudad de México un importante equipo de arquitectos e ingenieros de la Secretaría de Obras Públicas (unas 80 personas) se reunió con el italiano para discutir los programas arquitectónicos y urbanísticos de los juegos. Más aún, dirigentes y técnicos del comité organizador viajaron a Roma para recibir informes e instrucción ese mismo año. Pero también es verdad que en septiembre de 1964 un "numeroso grupo" de mexicanos viajó a los juegos de Tokio para enterarse de la organización nipona. ${ }^{30}$

Bien vistas las cosas, es probable que no haya habido un "modelo", si entendemos por tal una serie de lineamientos normativos o prescriptivos. A la pregunta expresa “¿qué olimpiada ejerció mayor influencia en la organización y el estilo de la de México?", Ramírez Vázquez respondió, ecuménicamente, "todas". 31 ¿Exagera?, no importa. Más significativo resulta en cambio el hecho de que al llegar Ramírez Vázquez a la presidencia del comité encontrara una libertad relativa para crear su propia imagen/proyecto. Esta construcción exigía una suerte de

30 Como se observa, la vindicación del modelo romano viene de los propios italianos; véase por ejemplo, "Los juegos de 1968 en México en el espíritu de Roma", Corriere de la Sera, 29 de diciembre de 1965; "Garroni regresa a México. La antorcha sobre la pirámide", Corriere dello Sport, s. a., y "Marcello Garroni al comité organizador", 16 de junio de 1965 , todos en ACOJO, caja 386, exp. 477; Fransesc Muñoz ha señalado que la planeación y ejecución de la Villa Olímpica se hizo desde la perspectiva del modelo romano: Muñoz, "Historic", s. a., p. 18. Sobre el viaje a Tokio, Alejandro Ortega San Vicente, "Los juegos de la XIX Olimpiada”, septiembre de 1998 en DPRV.

${ }^{31}$ Entrevista con PRv, 24 de septiembre de 1999. 
lectura crítica tanto de la historia como de las circunstancias olímpicas del momento; exigía además una especie de síntesis doctrinal, con un mínimo nivel de abstracción, que incorporara prioridades, énfasis, estilos propios: una olimpiada en México ¿para qué?, era la pregunta que los organizadores se hacían a sí mismos y hacían a los otros. ${ }^{32} \mathrm{El}$ asunto parece retórico; no lo es porque cada una de las respuestas posibles -siempre hay más de una, Isaiah Berlin dixit- tendrá consecuencias en las cosas. ${ }^{33}$

En marzo de 1967 Ramírez Vázquez se reunió durante tres días con uno o más miembros de su equipo para definir el sentido del trabajo editorial del comité organizador. Ya sea por lo que Ramírez Vázquez dijo en aquella sesión, ya sea por un trabajo de "traducción" de parte del autor de la nota, el resultado fue una verdadera declaración de principios sobre el sentido de la olimpiada de 1968. De esto último hay pocas dudas, digo yo, pues la sintaxis es inequívoca:

Los objetivos que el comité organizador atribuye a los juegos de la XIX Olimpiada y conforme a cuya naturaleza deberán concebirse y realizarse sus varias publicaciones son los siguientes:

${ }^{32}$ Interrogar una celebración, una festividad, un rito público conlleva más de un peligro metodológico para el historiador; el principal de ellos -juzgo yoes la "sobreinterpretación" del pasado, que no es otra cosa que el olvido de la literalidad de los actos y las palabras. Al respecto véase $\mathrm{Eco}$, Limites, 1998, pp. 9-19.

${ }^{33}$ Conozco dos estudios que discuten con seriedad el asunto de la creación de un discurso olímpico específico: MacAloon, "Olympic", 1996, pp. 29-44, y Hargraves, Freedom, 2000, pp. 39-57. a) Lograr, simultáneamente a la celebración de las competencias atléticas, la presencia activa del arte y la cultura, en cuyo ámbito logran los hombres un mejor entendimiento.

b) Restaurar, así, en México, las nobles manifestaciones del espíritu que enaltecieron en sus orígenes a las Olimpiadas y a otros juegos helénicos.

c) Conferir a los juegos el carácter de un festival de la juventud, a cuya fuerza y belleza debe ser consustancial el ejercicio de la inteligencia y la formación de la sensibilidad.

d) Asociar, por ello, a la confrontación de valores físicos, la exaltación de la confraternidad humana, expresada en los ideales de solidaridad, justicia y paz internacional.

e) Mostrar al mundo, en suma, lo mejor que ha logrado la humanidad en beneficio de sí misma.

Ramírez Vázquez sigue adelante. Ahora identifica el papel de los juegos olímpicos para

consagrar universalmente una imagen de México como una nación empeñada en conciliar:

a) La soberanía con la no intervención.

b) El nacionalismo con la universalidad.

c) La convivencia internacional con la paz.

d) El desarrollo económico con la justicia social.

e) El bienestar material con la educación y la cultura.

f) La modernidad con la tradición.

En suma, remata Ramírez Vázquez, "a la imagen de una nación practicante de fórmulas de convivencia y desarrollo de validez universales, se añadirá la de un 
país con interés histórico, artístico y folklórico propios". ${ }^{34}$

Una de las consecuencias más importantes del documento anterior era la "promoción turística excepcional" que el país buscaba. Aquí el proceso de construcción de una imagen y un proyecto alcanza otro grado de concreción: ¿cómo pensar e impulsar una política de promoción y difusión de los juegos? Reconozco dos momentos diferenciados, que en sí mismos ilustran la maduración de una idea olímpica en México. A mediados de 1965 el programa de publicidad evidenciaba un fuerte carácter prescriptivo y utilitario, pedestre inclusive, pues consideraba que el aspecto más importante de los juegos sería "el impacto psicosocial" en "el pueblo mexicano". Ese impacto sería de orden "moral para nuestras mayorías". De ahí entonces que en la campaña publicitaria - planeada por el Consejo Nacional de la Publicidad, un organismo privadobuscara "enaltecer el honor [... y la obligación correlativa que representa [...] el compromiso adquirido". Y seguía, como si fuera una advertencia o un regaño anticipado: la gente deberá entender que "todos nosotros, no sólo las autoridades o los deportistas, somos directamiente responsables del concepto que nuestros visitantes tengan de México". Más dramático aún, Ramírez Vázquez recuerda que cuando tomó el cargo de presidente del comité estaba en marcha una campaña publicitaria cuyo eslogan era "Pórtate bien mexicano, porque va a venir la Olimpiada"; un indígena adolescente, huasteco para

${ }^{34}$ Dirección de relaciones públicas. Nota de la conversación con Pedro Ramírez Vázquez, 2, 4 y 8 de marzo, sin año [debe ser 1967] en ACOJO, caja 403, exp. 154. Puntos uno, dos y tres. más señas, era el encargado de transmitir el mensaje. ${ }^{35}$ Para ser una campaña de difusión, sonaba muy defensiva.

No sólo defensiva. Es probable que el programa de 1965 fuese anacrónico en cuanto a las técnicas propuestas. El peso fundamental de la campaña descansaba en dos modalidades: por una parte, conferencias impartidas por "grupos cívicos" (770 en la ciudad de México y 1300 en el resto del país) en escuelas, clubes, sindicatos, etc.; por otra, en la publicidad en periódicos, sobre todo en suplementos. Las conferencias tratarían de reforzar tres aspectos de la relación del público con los juegos: incrementar el conocimiento de los deportes olímpicos; sensibilizar a todos frente a la "responsabilidad del compromiso", y promover la "hospitalidad y deportivismo" del público. El proyecto consideraba que la difusión por cine, radio y televisión sería marginal en la campaña en virtud de un "muy alto desconocimiento [popular] de la mayoría de las 19 especialidades" deportivas. Por lo demás, el programa se caracteriza por expresiones tan conspicuas como "Responsabilidad Nacional", así, con mayúsculas. No menos notable era el hecho de que ese programa - a pesar de que su concepción y presentación estuvo a cargo de publicistas profesionales- no contempló la creación de la imagen gráfica de la olimpiada ni su promoción internacional. ${ }^{36}$

${ }^{35}$ Hay por supuesto una tradición que utiliza un festival o celebración pública como método de educación cívica y política de la población; consúltese Tenorio, “1910”, 2001, pp. 167-198, y Lorey, "Postrevolutionary", 2001, pp. 233-240.

${ }^{36}$ Consejo Nacional de Publicidad, "Presentación del programa de publicidad para los juegos olímpicos de 1968", 29 de agosto de 1965 en ACOJO, 
Las cosas cambiaron, y mucho. Una campaña, de naturaleza muy distinta, estaba en marcha en 1968. El lema "Todo es posible en la paz" inundó la ciudad. La paloma de la paz ("que no fuera la del Espíritu Santo ni la [...] de Picasso", recomendó Ramírez Vázquez a sus creadores), sobria, elemental, saturó asimismo la ciudad. Desde el comité organizador se optó por celebrar lo que podríamos llamar la dimensión universal de los juegos. Mientras que el documento de 1965 es un programa didáctico, de educación cívica, para un pueblo recalcitrante y poco confiable, el programa de junio de 1968 habla de otra cosa y en otro tono: "en razón de su carácter universal, los juegos olímpicos representan para el país anfitrión la oportunidad de declararse hermano de todos los países de la tierra", postula; los juegos serán la "fiesta de todas las naciones", promete; al hermanarse el "deporte con las manifestaciones del arte y de la ciencia, se abarcan todos los campos de la expresión humana", declara; en fin, "la fiesta olímpica [adquirirá] la dimensión de una celebración total". ${ }^{37}$ En el fraseo encuentro otro tono y aun otro ritmo. Pero asimismo un concepto distinto: en junio de 1968 la difusión y promoción de los juegos ya no estaba ligada a una educación cívica, ni especulaba sobre la naturaleza y la urbanidad del público. En términos

caja 382, exp. 2018. Hay otros documentos complementarios en el mismo tono, en la misma caja y expediente: de Raymundo Cuervo (Noble y Asociados) a Clark Flores, 25 de enero de 1966; de Cuervo a López Mateos, 27 de junio de 1966. Para la imagen del indio huasteco, véase Rivera, "Diseño", 1999 , p. 33.

37 "La publicidad turística y la XIX Olimpiada", 11 de junio de 1968, en ACOJO, caja 403, exp. 159Iv; Rivera, "Diseño", 1999, pp. 33-34. de los argumentos, la olimpiada dejó de ser el examen final de civismo (como se concebía en la campaña de 1965) y quiso ser un proyecto ecuménico y celebratorio.

Honrar una "celebración total" implicaba la creación de un lenguaje. Según Pedro Ramírez Vázquez, el diseño gráfico moderno en México nació con los juegos olímpicos de $1968 .{ }^{38}$ Esta afirmación es un dato central para entender la creación de un discurso olímpico propio. Para Ramírez Vázquez uno de los peligros más importantes que enfrentaba la olimpiada mexicana era quedar atrapada en las ideas congeladas de lo mexicano: "no quiero un sombrero de charro", le dijo al jefe del diseño olímpico Eduardo Terrazas. Otro diseñador recuerda una preocupación omnipresente en el comité organizador: alejarse "de los estereotipos". Esta política de comunicación de los juegos es quizá más clara cuando observamos la forma como se integró el equipo de diseño. El comité organizador recurrió a dos expedientes: por un lado, organizar un equipo de trabajo con los maestros y alumnos de la única escuela de diseño gráfico en la ciudad de México en ese entonces (la de la Universidad Iberoamericana); por otro, se recurrió a las relaciones personales de los miembros del comité para reclutar un equipo de diseñadores extranjeros jóvenes que en ese momento gozaban de un prestigio incipiente por su trabajo. ${ }^{39}$ No juzgo el diseño gráfico de los juegos. Me interesa subrayar en cambio la ambición de los organizadores: generar una apropiación plástica y simbólica de los juegos,

${ }^{38}$ Entrevista con PRV, 24 de septiembre de 1999.

${ }^{39}$ Rivera, “Diseño", 1999, p. 28. Véase además el testimonio de Manuel Villazón, sin título, s. a., [debe ser septiembre, 1998], en DPRV. 
sin extenuar el mensaje en la promoción turística o en la didáctica cívica.

Pero la respuesta más original e importante, que mantuvo los juegos en la promesa del intercambio dialéctico entre lo local y lo universal -eso que tanto preocupaba a Ramírez Vázquez-, fue la olimpiada cultural. En la construcción de una imagen/proyecto de los juegos, la olimpiada cultural fue uno de los elementos más originales y más poderosamente identitarios del 68 mexicano. La olimpiada cultural fue un mundo en sí mismo, un aleph artístico, científico y tecnológico. Pero adelanto un elemento que me parece esencial, y que sugiere un cambio de grandes dimensiones en la imagen asumida y en la proyección de la cultura mexicana moderna: la olimpiada cultural no fue una hermenéutica y ni siquiera una introspección en esa cosa llamada el ser mexicano. Tampoco dominó sólo un ánimo museográfico que exhibiera -urbe et orbi- lo que fuimos y lo que somos. Con la olimpiada cultural no hay un viaje promocional o celebratorio, ni es manifiesto el deseo -siempre histérico, Freud dixitde convencer a los otros. La olimpiada cultural, con todos los usos políticos que se le atribuyan, quiso ser la puesta en escena de una enciclopedia del mundo; en todo caso, pretendió ser la representación plástica del estado del arte en la década de 1960. Hubo algo del nosotros somos; pero hubo mucho más del ellos son, ellos vienen ${ }^{40}$

\footnotetext{
${ }^{40}$ Según yo, es justamente lo contrario a la actitud que domina buena parte de la presencia mexicana en las ferias internacionales al cambio de siglo XIx; debe revisarse la obra más importante sobre la construcción de una imagen mexicana en el mundo poco antes y después de la revolución: Tenorio, Mexico, 1996.
}

Pedro Ramírez Vázquez se atribuye la idea de una olimpiada cultural. En su testimonio, él habría hecho una nueva lectura de los juegos griegos para descubrir que éstos no eran solamente competencias atléticas sino certámenes de poetas, escultores y dramaturgos: cada deporte era replicado por un arte. A partir de este diagnóstico, se perfila la posibilidad de abrir los juegos, esto es, de redistribuir las expectativas, las responsabilidades y los alcances del año olímpico. Ramírez Vázquez concibió entonces un plan para invitar a cada uno de los países concurrentes a los juegos para que, a sus propias expensas, enviaran además una delegación cultural a México. ${ }^{41} \mathrm{Al}$ contrario de las competencias deportivas, constreñidas a las dos semanas que establecen las regulaciones del Comité Olímpico Internacional, la olimpiada cultural se escenificaría a lo largo de todo el año. Había aquí una ventaja adicional para los organizadores de los juegos: los actos culturales y la promoción alrededor de ellos iría calentando la ciudad, iría preparando la ciudad para las dos semanas de octubre. ${ }^{42}$

En el cuadro 1 se puede observar el esquema de la olimpiada cultural. No es difícil adivinar la idea general que la sustenta: arte, mundo, juventud, tradición y modernidad son ideas genéricas; son, por decirlo así, las trabes en el edificio/ mundo de la retórica olímpica mexicana.

${ }^{41}$ Rivera, “Diseño", 1999, pp. 16-17.

42 Para Jorge Volpi los poco más de diez meses que anteceden al 12 de octubre de 1968 fueron vividos en México en una suerte de trance teleológico; aunque peligroso para el historiador, el argumento de Volpi debe ser considerado para evaluar el ánimo colectivo en la ciudad. Consúltese Volpi, Imaginación, 1998 , especialmente, pp. 26 y ss. 


\section{SECUENCIA}

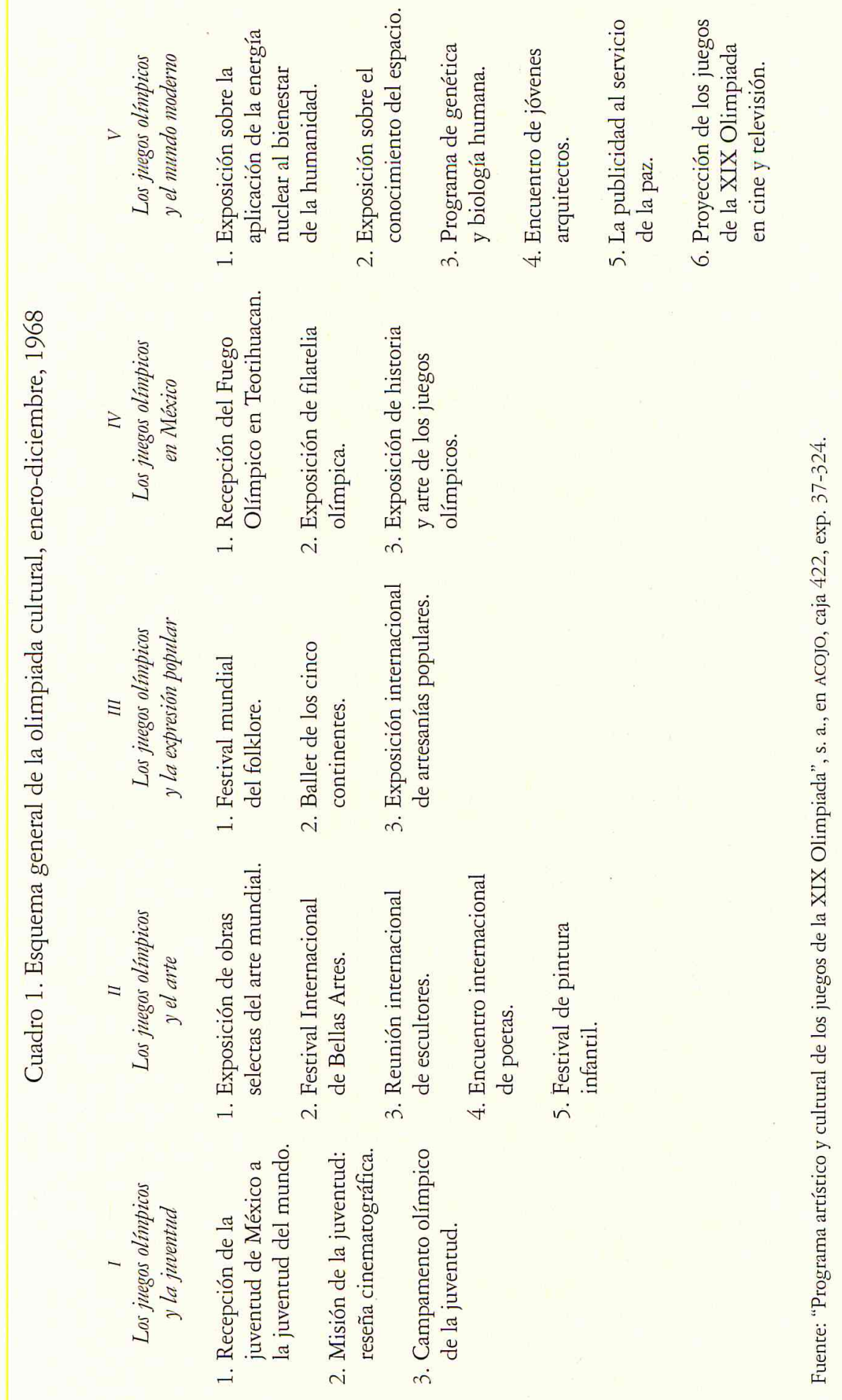


El mobiliario a su vez es refinado, elegante, indiscutible: poesía, música, danza, arquitectura, ciencia.

No es necesario interpretar en demasía. Los organizadores fueron siempre muy explícitos respecto a lo que esperaban de la olimpiada cultural. En un texto atribuido a Gustavo Díaz Ordaz, éste declaraba que

en fuerza física, en extensión territorial, en fuentes de riqueza, en desarrollo económico y en otros órdenes, podrán destacar determinadas naciones; en elevación del pensamiento, ninguna nación, ningún grupo de hombres puede considerarse superior a los demás.

Otra validación de la olimpiada cultural corre en el mismo sentido. Ella busca "una mayor proyección espiritual: hermanar el arte y el deporte, el cuerpo y el intelecto, [reunir los] juegos olímpicos del deporte, de la cultura [y] de la paz". 43

Por lo pronto, debo insistir en la combinación -ciertamente no muy comúnde personajes, ambientes y situaciones que semejante proyecto suscitó. Un testigo privilegiado recuerda la presentación del poeta soviético Eugene Evtuchenko nada menos que en la Arena México, uno de los locales más típicos para la práctica del boxeo profesional. Ante 12000 personas, el poeta fue anunciado por el escritor mexicano Juan José Arreola en el inconfundible estilo de una función de box: "Eeeeeeestimable público... en eeeessssta esquina... de setenta y dos kilos y uno ochenta y cuatro de estatura... EEEEeeeeeeevtuchenko". El poeta leyó su obra en español

43 “Programa...", s. a., en ACOJO, caja 422, exp. 37-324. y ruso. "Fue noche de apoteosis", dice la crónica. Tal vez, pero es más seguro concluir que el efecto fue el buscado por los organizadores: un recital de poesía de un autor soviético de fama mundial (bonito gesto no alineado en plena guerra fría y en pleno 68) frente a miles de personas, en un local popular de la ciudad de México, y con la asistencia siempre importante de periodistas de todo el mundo. ${ }^{4}$

Los ejemplos de este dispositivo de legitimación de todo el esfuerzo olímpico son muchos, e ilustres: Maurice Béjart y su ballet (o Martha Graham o John Cage o Alicia Alonso o el Ballet del Senegal); Maurice Chevalier (o Ella Fitzgerald y Duke Ellington); así por el estilo. Recientemente, Eric Zolov ha reconstruido el proceso de reelaboración y actualización del estereotipo mexicano en la cultura popular, en algunos medios intelectuales y en los gobiernos estadunidenses de las décadas de 1950 y 1960 . La construcción de una imagen de otro México, moderno, donde la "siesta terminó" y el "mañana" es un adverbio de tiempo, pero no una coartada para el desorden y la irresponsabilidad, ciertamente se vio beneficiada por la sede olímpica. No es difícil imaginar que el gobierno mexicano aprovechó las circunstancias para mostrar "otro" rostro en anuncios en periódicos y revistas (en The New York Times o Life por ejemplo), en cortometrajes para cine y televisión o en carteles. ${ }^{45}$

Pero yo dejaría aquí el punto, porque extenuarlo es peligroso para cualquier explicación histórica. Los grandes proyectos materiales de los Estados modernos se

\footnotetext{
${ }^{44}$ Óscar Urrutia Tazzer, "Olimpia 68”, julio de 1998 en DPRV.

45 Zolov, "Discovering”, 2001, pp. 234-272.
} 


\section{SECUENCIA}

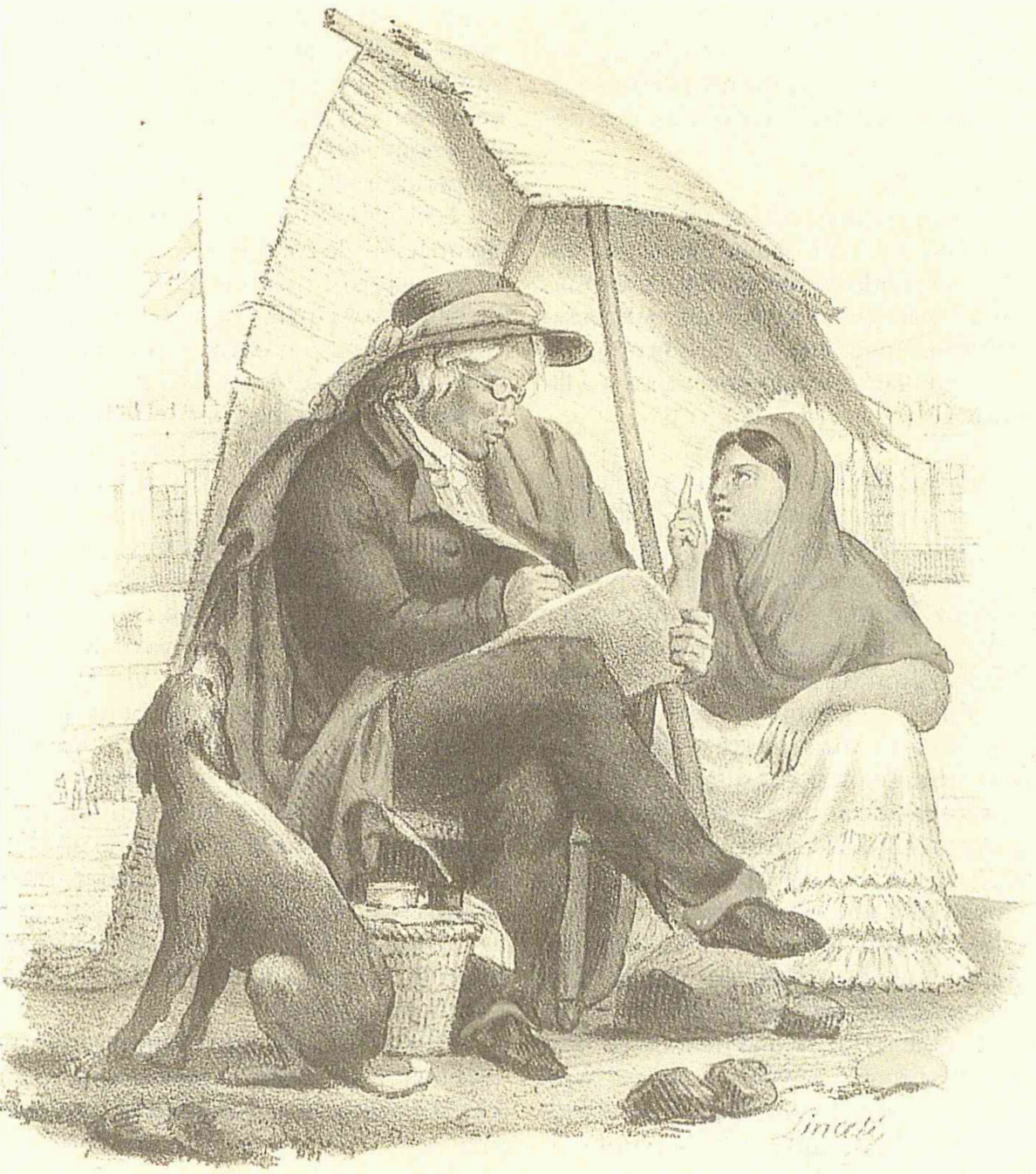

Claudio Linati, Ecrivain public, sur la grande place à Mexico. 
presentan necesariamente con una faceta simbólica y publicitaria. Pero de ahí no se infiere (o al menos no lo infiero yo) que la organización de unos juegos olímpicos (o la construcción de la Ciudad Universitaria o el Museo de Antropología) se haga sólo para impresionar o convencer a "los otros" (por ejemplo al gobierno estadunidense o a los editores y lectores de The New York Times o Life). En cambio, debemos asumir que el poder político ejercido para alcanzar y consumar objetivos y proyectos concretos es una autoafirmación y un constante escrutinio sobre sus posibilidades. Dicho de otra forma (y pase por un ejemplo), al construir una red de caminos en México (o presas o escuelas o sistemas de agua potable), los gobiernos de la posrevolución no sólo han construido la obra físi$\mathrm{ca}$, sino en buena medida han creado al empresario, al consumidor y (sobre todas las cosas) se han recreado a sí mismos. ${ }^{46}$ Al término de 1968, Óscar Urrutia, quien fue el coordinador de la olimpiada cultural, visitó a José Luis Martínez, director del Instituto Nacional de Bellas Artes. Éste le mostró a Urrutia el estado contable del Palacio de Bellas Artes y preguntó: "¿de qué color es la cifra final, Óscar?" "Negra", contestó Urrutia. "Debes estar orgulloso", concluyó Martínez, "es el primer año que el balance contable de Bellas Artes está en números negros". 47 Abarrotar un año completo el Palacio de Bellas Artes es un acto de poder.

46 Para avanzar en esta línea de interpretación han sido muy útiles para mí los trabajos de Connolly, “Introducción”, 1999; Williams, Dream, 1982, y Waters, Re-mapping, 1999.

47 Óscar Urrutia Tazzer, "Olimpia 68”, septiembre 1998 en DPRV.
¿CÓMO HACER UNOS JUEGOS OLÍMPICOS EN UNA CIUDAD PLEBEYA? CONTEXTO Y NATURALEZA DE LA INTERVENCIÓN URBANA

En 1954 un periodista preguntó al arquitecto y crítico Mauricio Gómez Mayorga: "¿qué le cambiaría usted a la ciudad de México?" Su respuesta fue aleccionadora: "Yo le cambiaría [...] todo: la ubicación, la traza, la extensión; la forma y el color de los edificios; el rostro y la gente; la mayor parte de las joyas coloniales, poscoloniales y futuras." Gómez Mayorga sólo conservaría Chapultepec, Ciudad Universitaria, Paseo de la Reforma (pero únicamente la traza y los árboles), y algunos rincones de San Ângel y Coyoacán. "Nada más", dijo. Recordó además que había simulado muchas veces, en planos y pizarrones, el trazo de nuevas calles, avenidas y free ways, y había derruido imaginariamente manzanas enteras. Pero quizá resultase más práctico -según él-arreglar "la irremediable, irreparable, intrínsecamente fea" ciudad de México "desde un helicóptero y con unas pequeñas bombas de hidrógeno a la mano". 48

Estoy casi seguro de que Mauricio Gómez Mayorga es una versión mexicana de lo que un historiador ha llamado "el modernismo reaccionario", es decir, esa tendencia que mostró una parte de la cultura alemana del 900 para integrar y utilizar ciertos valores y hallazgos del mundo moderno (la ciencia, la tecnología, la planificación, la apelación popular en la política) sin recurrir a aquellos otros considerados débiles o decadentes o ajenos a una tradición supuesta (el republicanismo, el liberalismo, la forma de gobierno repre-

4s Gómez, ¿Qué?', 1957, pp. 13-14. 
sentativo, ciertas vanguardias artísticas). ${ }^{49}$ Aunque el símil no es exacto y tal vez es injusto - Gómez Mayorga fue un defensor ferviente del cubismo y del movimiento moderno en la arquitectura, muy al contrario de la actitud nazi frente al arte y la arquitectura modernos-, ${ }^{50}$ ciertamente es aplicable en cuanto que es evidente su deseo fáustico de reconstruir la ciudad desde todos los postulados modernos, excepto uno: la gente.

Gómez Mayorga es una hipótesis. Él encarna un tipo de percepción y respuesta posible ante los problemas urbanos de la capital de la república hacia las décadas de 1950 y 1960. Seguramente la suya era una posición extrema y no muy común, pues combinaba un fuerte vanguardismo estético con una actitud claramente recalcitrante respecto a la gente común y a las relaciones de ésta con la ciudad y sus edificaciones. De cualquier forma, sus ideas siempre deben ser consideradas como una posibilidad dentro del programa de la cultura moderna: hacer tabla rasa del pasado, convertir en polvo todas las densidades sociales, políticas, urbanísticas y arquitectónicas, y erigir, simplemente, otra ciudad sobre los escombros de la antigua. ${ }^{51}$ Esto,

${ }^{49}$ Herf, Modernismo, 1993.

${ }^{50}$ Que las posiciones estéticas de Gómez Mayorga son claramente cercanas a las vanguardias del siglo $\mathrm{xx}$ se puede constatar en su texto "Tres ensayos polémicos" recogido en Ensayos, 1986, pp. 62-87. Para la ideología völkisch y sus diatribas contra la arquitectura moderna, véase Taylor, Word, 1974, especialmente las pp. 103-125.

${ }^{51}$ El dilema de "destruir-lo-viejo-para-construirlo-nuevo" es tema central en la historia de la ciudad y la cultura moderna, al menos en los dos últimos siglos; muy importantes para mí han sido dos trabajos: Berman, Todo, 1988 (la segunda parte, sobre todo), y Canetti, "Hitler", 1981. que para algunos modernistas es un sueño, para otras sensibilidades (y pienso en cierto tipo de políticos y arquitectos, en casi todos los antropólogos, historiadores y sociólogos, ${ }^{52}$ y en ciertos grupos de vecinos) es una verdadera pesadilla.

La intensidad, localización, extensión y estilo de las intervenciones urbanas representaban uno de los asuntos más delicados en la política local y el gobierno en la ciudad quizá desde el término de la segunda guerra mundial, y claramente en la década de $1960 .^{53}$ Una historia política y social asociada a una historia de las inter-

${ }^{52}$ Pero de cualquier forma juzgo desafortunada, injusta y endeble -conceptual e históricamente- la crítica destemplada que James Scott ha dirigido a pensadores como Le Corbusier o a experimentos tan fundamentales para la experiencia urbana moderna como el de la planeación y construcción de Brasilia; véase su Seeing, 1998, cap. 4. Para contrastar el marcado pesimismo (y a veces se diría la paranoia) de Scott frente a un proyecto como el de Brasilia, véase el apasionante trabajo de Herbert, "Brasilia", 1998.

${ }^{53}$ Por motivos sólo analíticos, podemos imaginar que lo que llamo una intervención urbana -es decir el conjunto de planes y acciones que el gobierno nacional y/o local concibe y ejecuta por sí mismo o por medio de empresas contratistas- toca tres dimensiones de la ciudad: la vivienda, la infraestructura (redes hidráulica y de energía, vías de comunicación, transporte, edificios de gobierno) y los equipamientos para la educación, la salud, la cultura y el esparcimiento (parques, escuelas, hospitales, museos, estadios, auditorios, etc.). Básicamente, esa intervención puede darse en dos escenarios: en espacios vacíos, con el fin de alentar el desarrollo y crecimiento de una nueva área de la ciudad, por ejemplo (psendourbias); o en espacios ya habitados, para crear o modernizar vías de comunicación, servicios, viviendas o equipamientos (regularización). En esta dicotomía estoy en deuda con el trabajo, claro y útil para mis fines, de Choay, $\mathrm{Mo-}$ dern, 1969, pp. 7-31. 
venciones en la ciudad de México está apenas en gestación. ${ }^{54}$ Pero hasta donde el estado del arte nos permite aventurar, sugiero que las decisiones políticas y urbanísticas -son ejemplos- para construir Ciudad Universitaria, para ejecutar los proyectos de reforma de la ciudad vieja (la restauración del Centro Histórico, la regeneración de la "herradura de tugurios", la restauración de la catedral después del incendio de enero de 1967) o para construir el Metro (el sistema de transporte subterráneo), fueron casi siempre empresas arduas organizativamente, muy discutidas en la opinión pública y casi siempre precarias financiera y políticamente. ${ }^{55} \mathrm{La}$ evidencia física de esos edificios, de esos trenes, de esos monumentos, no puede hacernos olvidar que su existencia no es el producto de un Estado omnipotente y rico, sino el milagro de un Estado pobretón y anémico que con frecuencia no ha sabido ni cobrar impuestos. Que ese Estado haya construido en la capital nacional Ciudad Universi-

${ }^{54}$ Un texto muy importante sobre el periodo es el de Davis, Urban, 1994, especialmente las pp. 63 y ss. Véase asimismo Sánchez, Ciudad, 1999, pp. 164-165, y Ward, México, 1991, especialmente pp. 161 y ss.

${ }^{55}$ Una fuente para entender el asunto del plano regulador, los grupos de interés y la debilidad del gobierno para tomar decisiones entre 1950 y 1952 es el trabajo de García, Reforma, 1972. Para los avatares alrededor de la Ciudad Universitaria, Díaz de Ovando, Cindad, 1979, pp. 79 y ss. Para discutir la formación de grupos en pro y en contra del Metro en la década de 1960 véase Davis, Urban, 1994, pp. 137218. Hay elementos para entender la batalla campal entre renovadores y tradicionalistas con motivo de la restauración de la catedral en Arquitectos de México, núms. 53-55, enero de 1968, y en Piña, Restauración, 1970. taria, Tlatelolco o el Metro o, más aún, que haya organizado unos juegos olímpicos, valida el aserto de Alan Knight: busquemos en el horizonte de la historia posrevolucionaria un gigante, sí, pero con pies de barro -nunca un big brother.

En el camino de los juegos de 1968 claramente se percibe la certeza de los organizadores de que las decisiones sobre el estilo y la escala de la obra olímpica deben ser prudentes, autocontenidas, por decirlo de alguna forma. No hay evidencia de que en el comité organizador, y menos en el gobierno, alguien haya imaginado el año de 1968 como la coartada de una gran transformación urbana: la ciudad y sus pobladores eran "un problema" de gobierno, y no el material de una utopía y ni siquiera el de una reforma. Vicente Medel, uno de los responsables de la localización de las instalaciones olímpicas, resume con toda precisión las prioridades de los organizadores.

Dos fueron los objetivos fundamentales al hacer el planeamiento general de las instalaciones olímpicas: cumplir con los requisitos olímpicos por medio de una inversión adecuada a las posibilidades del país y asegurar en lo posible un uso posolímpico de todas las instalaciones. ${ }^{56}$

Ni utopía ni reforma. De cualquier forma, había que organizar los juegos y tomar las medidas conducentes. El caso de la defenestración de Ernesto P. Uruchurtu como jefe del Departamento del Distrito Federal (esto es, como alcalde de la capital, pero con la peculiaridad de que ese cargo no era electivo sino un nombramiento directo del presidente de la re-

${ }^{56}$ Medel, "Urbanística”, 1968, p. 40. 
pública), en septiembre de 1966, muestra que tampoco las dudas metódicas respecto a la viabilidad de los juegos eran posibles en aquellas circunstancias. Dos cosas pueden decirse de Uruchurtu: la primera es que, al momento de su despido, llevaba la friolera de catorce años en el cargo, esto es, había servido en las presidencias de Adolfo Ruiz Cortines (1952-1958), de Adolfo López Mateos (1958-1964) y dos años en la de Díaz Ordaz (1964-1966); se trataba pues de un político de altos vuelos, muy experimentado en la administración de la ciudad, con importantes alianzas políticas locales.

La segunda cuestión son los indicios de su mala relación con el presidente Díaz Ordaz y los efectos de ese conflicto en la organización de la olimpiada. Ni Uruchurtu ni el gobierno de la ciudad tuvieron nunca representación formal en el comité organizador. Cosa más interesante aún si consideramos que una sede olímpica se otorga siempre a una ciudad y nunca a un gobierno nacional. Una explicación de esa descortesía parece probable: a Uruchurtu nunca le gustaron los proyectos grandes. Diane Davis sostiene que don Ernesto fue, desde fines de la década de 1950, un decidido opositor de la construcción del Metro; fue también reacio a cualquier proyecto de renovación mayor del Centro Histórico. Si los juegos olímpicos no fueron tampoco santo de su devoción es difícil saberlo; en todo caso es una evidencia muy incómoda el hecho de que la construcción de la obra olímpica comenzó, toda ella, sólo después de su salida del gobierno de la capital. ${ }^{57}$

${ }^{57}$ Noticias biográficas de Uruchurtu se encuentran en Camp, Mexican, 1993, p. 710. Una caracterización muy interesante de su gobierno se encuentra
Pero incluso con la expulsión de Uruchurtu de la aventura olímpica (y de la política mexicana), el tono prudente de los organizadores se mantuvo. Adelanto una consecuencia de estos ambientes: la construcción de un discurso de identidad para la olimpiada mexicana no se vinculó a la aventura tecnológica, estilística o de escala de la obra olímpica. Las ciudades para las que tenemos una literatura más o menos desarrollada (Berlín en 1936, Roma en 1960, Tokio en 1964 y Barcelona en 1992) muestran las distintas modalidades y fines de una intervención urbana, y nos ayudan a identificar las especificidades del caso mexicano. Es bueno saber que, con mayor o menor éxito, cada ciudad debió convertirse en una ciudad olímpica. Ciertamente las magnitudes técnicas, materiales y financieras de las intervenciones variaron, como variaron los lenguajes y los recursos estilísticos comprometidos en la arquitectura, la urbanística y la gráfica. ${ }^{58}$ Pero en estos cuatro casos claramente los organizadores aprovecharon la coyuntura para asociar la olimpiada con el cambio urbano (se haya logrado éste o no) y, por lo tanto, con el despliegue de recursos materiales, técnicos

en Davis, Urban, 1994, pp. 137 y ss. La enorme conmoción política que originó su despido del gobierno de la ciudad puede documentarse en la revista Politica, 15 de septiembre de 1966 , pp. 10-12 y además en el suplemento en ese mismo número.

${ }^{58}$ Uno de los pocos trabajos que ofrecen una panorámica histórica amplia de estos problemas -pero con un método más bien impresionista- es el bello libro de Gordon, Olympic, 1983, especialmente las pp. 60-108. Aunque su temática es más amplia (y en el caso del segundo libro que cito abajo, tópica), véase los trabajos de Roche, Mega-Events, 2000, pp. 125158, y Lenskyj, Inside, 2000, pp. 93-105. 
y financieros. No es difícil imaginar que el modelo político nacional y local, los ambientes político-ideológicos vigentes y las prioridades de los gobiernos en cada coyuntura, pesaron en el cálculo de las ganancias y de los costos políticos de las obras. $^{59}$

Concebir y vender la idea de una olimpiada barata, en cambio, sería una de las aportaciones más originales de la experiencia mexicana. El adjetivo (barato) es importante en esta investigación, y aun diría que estratégico: es una de las fuentes de legitimidad (en México y en el extranjero) de la aventura. El cuadro 2 muestra que efectivamente los juegos de la ciudad de México han sido los menos costosos (en términos absolutos) desde la olimpiada de Roma en 1960, y tienen el segundo per capita más bajo (esto es, costo por atleta), sólo comparable al de Los Ángeles 1984, para todo el periodo 1964-1988. Pero quizá el dato más dramático es la diferencia, inquietante por su magnitud,

\footnotetext{
59 Suponiendo que sea suficiente ese universo de cuatro experiencias olímpicas -y no lo es- distingo tres modelos de intervención y organización de los juegos: el primer tipo es el que llamo aquí la olimpiada de Estado en un régimen totalitario, es decir, Berlín, 1936; el segundo, la olimpiada de Estado en un régimen semiautoritario, al estilo Tokio, 1964, y el tercero, el tipo de experiencias olímpicas en modelos políticos descentralizados y competitivos desde el punto de vista electoral, ideológico e incluso cultural, esto es, los casos de Roma, 1960 y Barcelona, 1992. Defino la tipología anterior, que es claramente provisional, con el fin de contrastar las especificidades del caso mexicano en un avance posterior. Soy deudor de los siguientes trabajos: Mandell, Nazi, 1971; Large, Berlin, 2000, pp. 255 y ss.; Scobie, Hitler's, 1990; Taylor, Word, 1974; Fried, Planning, 1973, pp. 210 y ss.; Gordon, Olympic, 1983, pp. 60 y ss.; Hargreaves, Freedom, 2000; Martorell, Villa, 1992.
}

entre los costos de la olimpiada de Tokio en 1964 y los de la olimpiada de la ciudad de México.

Los testimonios disponibles muestran que los organizadores mexicanos entendieron el problema de la escalada de los costos y, tal vez no explícitamente, lo asociaron a una visión sobre la fragilidad o vulnerabilidad de los juegos en la política local. El presidente Díaz Ordaz sostuvo en septiembre de 1967 que se "procura" que las instalaciones olímpicas "tengan una utilidad social permanente y no sirvan exclusivamente de motivo de lucimiento para nuestra capital unos cuantos días" ${ }^{60} \mathrm{Al}$ año siguiente, y en pleno conflicto estudiantil, Díaz Ordaz confesó que al asumir la presidencia "uno de los muy preocupantes problemas" a la vista era "el grave compromiso que México había contraído" con motivo de los juegos olímpicos. El esfuerzo necesario para organizarlos "podía resultar superior a nuestras fuerzas, por la magnitud del cálculo presupuestal [...] cuyo monto era capaz de desquiciar nuestra economía [...]". Así las cosas, y dado que el de México "es un pueblo con muchas necesidades insatisfechas", se tomó la decisión de hacer una consulta con partidos políticos, líderes obreros y campesinos y organizaciones patronales, sobre la conveniencia de seguir adelante con la olimpiada. "Estábamos a tiempo [...] de declinar sin deshonor. Varias ciudades deseaban reemplazarnos", aseveró. Pero el resultado de la auscultación fue por demás claro: la organización de los juegos debía seguir adelante, a riesgo de comprometer el prestigio y el crédito internacional de México; en todo caso, su

${ }^{60}$ III Informe de gobierno, 1 de septiembre de 1967 en ACOJO, caja 394, exp. 20. 
Cuadro 2. Juegos olímpicos: costo en dólares de 1982 (1936-1988)

Sede $y$ año

Berlín 1936

Londres 1948

Helsinki 1952

Melbourne 1956

Roma 1960

Tokio 1964

Ciudad de México 1968

Munich 1972

Montreal 1976

Moscú 1980

Los Ángeles 1984

Seúl 1988
Costo total

(en dólares de 1982)

$$
\begin{array}{r}
217391000 \\
12266000 \\
\text { s. d. } \\
50236000 \\
240540000 \\
6612903000 \\
502873000 \\
1463760000 \\
2429996000 \\
2427185000 \\
525505000 \\
3420963000
\end{array}
$$

Atletas
participantes

4066

4099

s. d.

3342

5348

5140

5531

7147

6085

5353

7344

8465
Costo por atleta.

(en dólares de 1982)

53447

2992

s. d.

15031

44977

1208736

90919

204807

399341

453425

71555

404130

Fuente: Elaborado con los datos de Zarnowski, “Look”, 1992, núm. 1, pp. 30-31.

presupuesto se ajustaría para "presentarnos con decoro [pero] sin lujos inútiles". 61

En el mismo tenor, pero quizá más significativo por la audiencia a la que estaba dirigido su mensaje, Pedro Ramírez Vázquez declaró ante los miembros del Comité Olímpico Internacional:

Creo conveniente informar a ustedes que todas las obras que se realizan han sido proyectadas para cumplir con todos los requerimientos necesarios para llevar a cabo las competencias deportivas con absoluta eficacia, pero siempre con el propósito de que correspondan a necesidades y servicios de carácter permanente, pues creemos que los juegos olímpicos nunca deben provocar in-

61 "Comité organizador de la XIX Olimpiada. Central de documentación de prensa", septiembre de 1968 en ACOJO, caja 422, exp. 37-432. Véase Rodríguez Kuri, "Otro", 1998. versiones o construcciones que no correspondan a una utilidad social posterior, pues de ser así se convertirían en obras de dispendio, imposibles de realizar para países en desarrollo y desaconsejables por completo en una época en que las carencias sociales son de igual gravedad para todos los países. ${ }^{62}$

Es sintomático que los programas de promoción y difusión de la olimpiada no aislaran la naturaleza estética o técnica de la obra olímpica. Cualquier idea de explotar ciertos vanguardismos estéticos o técnicos quedó subsumida en una idea genérica sobre la circunstancia mexicana, sus potencialidades pero sobre todo sus limitaciones. Y esto a pesar de que la ar-

62 "Informe presentado por [...] Pedro Ramírez Vázquez [...] ante la LXV sesión del Comité Olímpico Internacional celebrada en Teherán", mayo de 1967 en ACOJO, caja 390, exp. 2676. 
quitectura mexicana se ha sentido casi siempre cómoda en su trato con las vanguardias del siglo xx (o como escribió Mathias Goeritz para nuestra tranquilidad, la arquitectura mexicana "no es una señora pequeñoburguesa que guarda una taza de porcelana sólo porque perteneció a la abuela anciana"). ${ }^{63}$ En una plática radiofónica, Ramírez Vázquez insistió en que la oferta mexicana era sobre todo la de unos juegos austeros, pues su "preparación no constituye, de ninguna manera, un derroche injustificado", ya que una "equilibrada planificación de las construcciones ha previsto su servicio posterior para el bien público". El conjunto de las obras olímpicas quedaría incluido, así, "dentro del desarrollo normal de la economía mexicana". Y si las instalaciones olímpicas mexicanas no son "las más bellas en la historia de los juegos olímpicos", de cualquier manera son prácticas y funcionales. "Las más bellas de la historia", un concepto arduo y tal vez inoperante. Tengo para mí que hubo apuestas estilísticas importantes en los juegos mexicanos, especialmente en dos edificios (el Palacio de los Deportes y la Alberca y Gimnasio Olímpicos). De cualquier forma, es probable que en México nadie haya experimentado lo que aquel nadador cuando ingresó la primera vez en la alberca olímpica que diseñó Kenzo Tange para los juegos de Tokio en 1964: "es la clase de lugar que uno espera al morir e ir al cielo". ${ }^{64}$

${ }^{63}$ Dos juicios sobre el ritmo de las relaciones entre la arquitectura mexicana y las vanguardias europeas se encuentra en Villagrán, "Foreword", 1967, pp. 9-14 y Cetto, Modern, 1961, p. 10; la cita en Goeritz, "Introduction”, 1969, p. 7.

64 Transcripción de la plática radiofónica núm. 66 "Funcionalidad de las instalaciones olímpicas",
Las palabras de Ramírez Vázquez fueron replicadas por otros artífices de los juegos en el mismo sentido pero con más detalle. Carlos Ortega Viramontes, uno de los arquitectos que hicieron el proyecto de la Villa Olímpica, lo dijo así:

El primer problema importante que nos planteó [el diseño de la Villa] fue el doble uso que se pretendía dar a los edificios. Para nosotros, sin embargo, fue mucho más importante la idea de hacer un condominio de habitación que el uso temporal de tres semanas que se iba a dar a la Villa Olímpica.

Otro arquitecto, Ramón Torres Martínez, recordó la presión permanente de los costos:

A nosotros se nos plantearon una serie de condicionantes del proyecto [de la Villa], todas ellas tendientes a que el costo fuera el mínimo, a que se analizaran los materiales del mercado [... ] a que se usara la estructura más económica y todo ello nos fue limitando muchísimo. ${ }^{65}$

En la primera parte del artículo recordé la noción de urbanismo vivo de Ramírez Vázquez. Este dispositivo suponía -debo insistir- un modelo de intervención urbana de bajo perfil en el planeamiento de los juegos. Urbanismo vivo es una mirada muy amplia, predispuesta a optimizar su propios recursos. Hacia el segundo semestre de 1966 los organizadores estaban ciertos de la necesidad de

s. a. en ACOJO, exp. 154-IV. Para el arrebato místico del atleta acuático, y para un juicio sumario de las instalaciones olímpicas de la ciudad de México, Gordon, Olympic, 1983, p. 82.

65 Torres, "Mesa", 1969, pp. 112-116. 


\section{SECUENCIA}

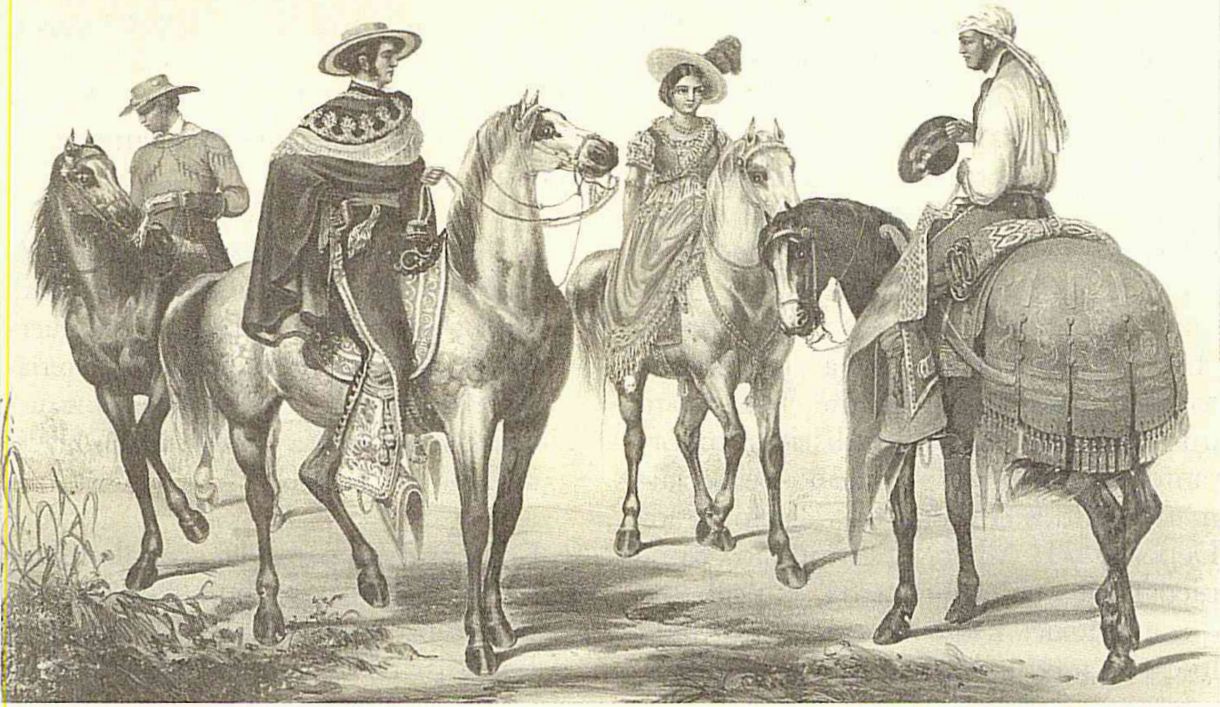

Karl Nebel, El hacendado y su mayordomo. 
articular una política que utilizara exhaustivamente la capacidad instalada de la ciudad en lo que se refería a los escenarios olímpicos, los servicios urbanos y las estructuras administrativas. En consecuencia, impulsaron una política que integrase a la oferta olímpica aquellos proyectos que -como la Villa Olímpica, el Estadio Azteca y las nuevas avenidas y free waysestaban ya previstos por algunas dependencias gubernamentales, y que sólo fueron reprogramados y ajustados en términos de los tiempos y normatividad de los juegos. ${ }^{66}$

El asunto de la capacidad instalada de la ciudad de México para responder a los requerimientos de la competencia se constituyó en un aspecto central en la idea de austeridad olímpica. Cuando se solicitó la sede ante el Comité Olímpico Internacional, uno de los argumentos más importantes era que la ciudad contaba ya con $70 \%$ de las instalaciones indispensables para realizar un evento de esa magnitud. ${ }^{67}$ No queda claro cómo obtuvieron los organizadores ese porcentaje. Según un cálculo mío (véase cuadro 3), nueve de los escenarios olímpicos en la ciudad fue-ron obra nueva, y otros nueve fueron remodelados y adecuados - en mayor o menor medida- para los juegos. Claro está que entre estos últimos se encontraba el Estadio Olímpico, que por definición

${ }^{66}$ Ramírez Vázquez siempre subraya esta opción. Véase Rivera, "Diseño", 1999, pp. 23-24. Además entrevista con PRV, 24 de septiembre de 1999.

${ }^{67}$ Varias veces los organizadores hicieron referencia al "70\%" de las instalaciones olímpicas. Ejemplos: borrador de un texto "Las Olimpiadas", s. a., y "Plática sobre la organización de la XIX Olimpiada en México", ca. enero o febrero de 1967 en ACojo, caja 403 , exps. 154 y 153 , respectivamente. es el centro de gravedad de una olimpiada. No obstante, cuatro de las obras nuevas aparecen como fundamentales, tanto por sus costos como por su significación deportiva, arquitectónica y urbanística: el Palacio de los Deportes, el complejo Alberca y Gimnasio Olímpicos, la pista de remo y canotaje de Cuemanco, y la Villa Olímpica. También podría considerarse en la misma categoría al Estadio Azte$\mathrm{ca}$, aunque su concepción, proyecto y financiamiento fue obra de una empresa particular $^{68}$

No conozco ninguna evaluación del impacto a corto y mediano plazo de la intervención urbana con motivo de la olimpiada. Por lo pronto, con el fin de dar sustancia a la noción de urbanismo vivo y de entender la disposición espacial de las instalaciones, identifico tres ámbitos que definen -o al menos ayudan a visualizar"la ciudad olímpica". El primero de ellos es un gran arco de equipamientos que va del noroeste al sureste, es decir, desde el Polígono de Tiro y el Centro Deportivo Olímpico Mexicano (al noroeste, en la frontera del Distrito Federal y el Estado de México), hasta el Canal de Cuemanco (al sureste, en las inmediaciones de Xochimilco). Tres obras constituyen los puntos medulares de este arco, desde el punto de vista arquitectónico y del paisaje urbano: el Estadio Olímpico de la Ciudad Universitaria, la Villa Olímpica y el Estadio Azteca. Este arco es estructurado por algunas de las avenidas o vías rápidas más importantes y reconocibles de la ciudad: Revolución, Reforma, Insurgentes y Periférico.

${ }^{68}$ Hay noticias sobre las circunstancias en que se originó y desarrolló el proyecto del Estadio Azteca -cuyo arquitecto fue Pedro Ramírez Vázquez, por cierto- en Ramírez Vázquez, 1989, pp. 161 y ss. 


\section{SECUENCIA}

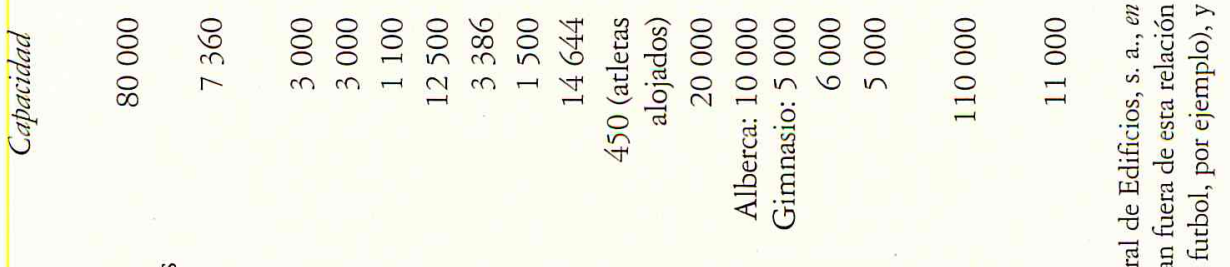

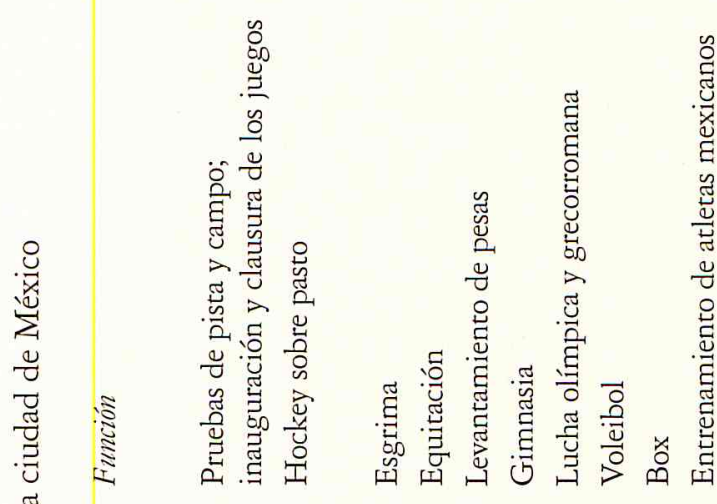
త్త ีำ

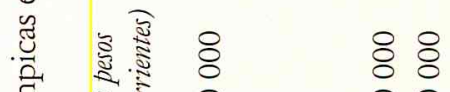

吾

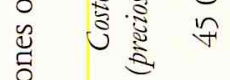

:

3)

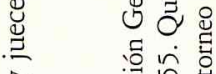

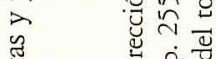

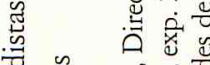

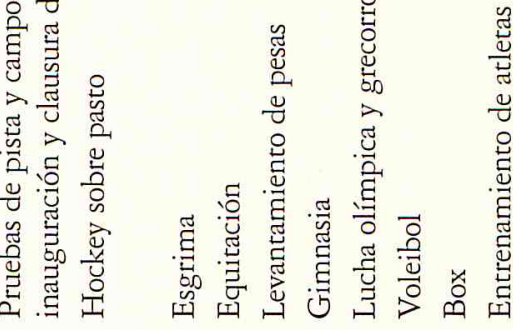

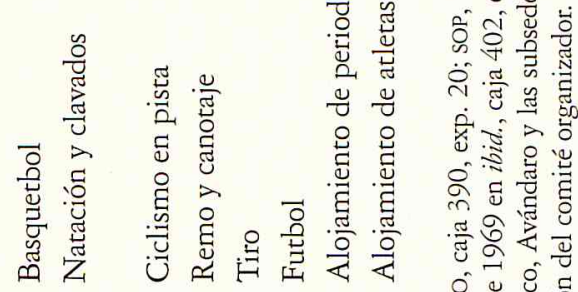

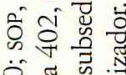

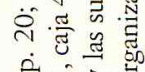

武语

웡

ठृ:

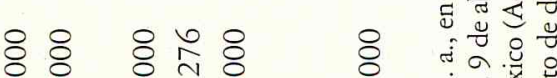

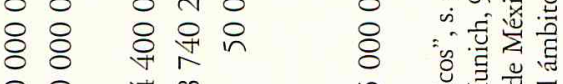

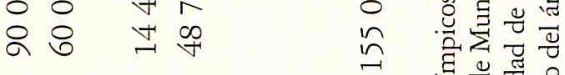

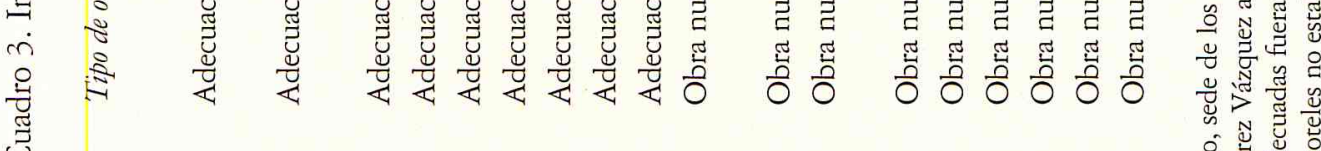

క

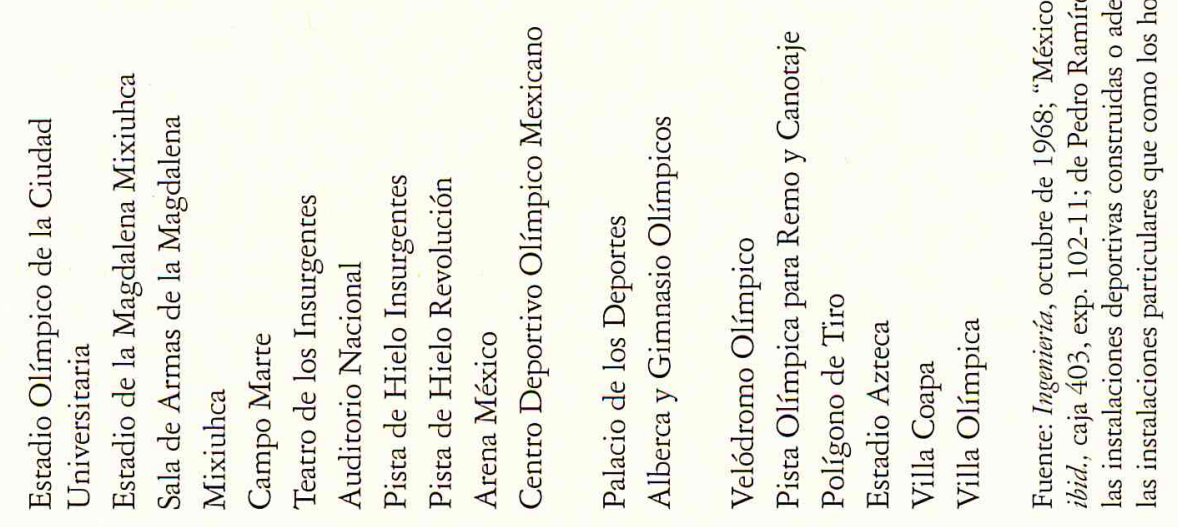


De hecho, Insurgentes, pero sobre todo Periférico, fueron prolongadas para completar la red de vialidades en la parte sur de la ciudad (véanse plano y cuadro 4).

Con toda seguridad este gran arco constituía la zona dorada de los organizadores, algo parecido a lo que Mauricio Tenorio quiso ver como la ciudad ideal del Centenario en 1910. Existe evidencia de que los planificadores de la olimpiada habían identificado la parte oeste y sur de la ciudad como el área más deseable para instituir algo parecido a un corredor olímpico. En un documento de los organizadores, éstos calificaban esa gran sección como "residencial, bien comunicada" y con un "paisaje urbano agradable". En cambio el centro, el centro-norte y el este de la ciudad eran catalogados como "comercial $[y]$ congestionada" e "industrial, obrera y popular sin circulaciones continuas". 69

Sin embargo, un segundo grupo de instalaciones olímpicas se encuentran justamente en la otra esquina de la ciudad, en el noreste; esta ubicación en principio desmiente las posibilidades del corredor olímpico. Aquí, tres equipamientos (el Velódromo, la Sala de Armas y el campo de hockey) son subsidiarios de una obra

${ }^{69}$ Tenorio, “1910”, 2001, pp. 170-181; Medel, "Urbanística", 1969, p. 41. Para uno de los pocos ejemplos de una historia de un grupo de trabajadores en esa zona "industrial, obrera y popular sin circulaciones continuas" véase el trabajo, ejemplar en muchos sentidos, de Bachelor, "Toiling”, 2001, pp. 273 y ss.; Rubenstein, "Bodies", 2001, reflexiona sobre el desplazamiento de muchas actividades urbanas desde el centro hacia el poniente y sur. Pueden seguirse esos desplazamientos, pero tal como los percibieron poetas y novelistas, en Quirarte, Elogio, 2001, pp. 529 y ss. olímpica mayor: el Palacio de los Deportes. La existencia previa del gran parque urbano (deportivo y recreativo) de la Magdalena Mixiuhca suponía una disponibilidad de espacio muy importante, sólo parcialmente aprovechada. Es probable que si los organizadores de los juegos de la ciudad de México hubiesen optado por la construcción de un gran complejo olímpico que concentrara todas (o casi todas) las instalaciones deportivas exigidas, habrían elegido la Magdalena Mixiuhca y las zonas aledañas. Desconozco si esta posibilidad fue contemplada en algún momento por los responsables, pero existía al menos un gran inconveniente para esta alternativa: el Estadio Olímpico, que es práctica y simbólicamente el corazón de los juegos, se encuentra en la esquina opuesta de la ciudad, en el suroeste, en Ciudad Universitaria.

Un tercer tipo de instalaciones olímpicas está definido -aunque muy débilmente- por la Arena México y el conjunto Alberca y Gimnasio Olímpicos. La primera se encuentra en el corazón de la ciudad vieja, en el Centro Histórico. El segundo, en el centro-sur. La Arena México era un viejo edificio, ya desde muchos años atrás sede de las funciones de box. La Alberca y el Gimnasio, en cambio, fueron construidos ex profeso para los juegos. En ambos casos estamos, sin embargo, ante sendos ejemplos de adaptación a la ciudad realmente existente. La Arena México está en realidad aislada, distante de cualquier otra instalación olímpica; pero en tanto lugar tradicional de la práctica del boxeo, no hubo dificultad en elegirla como la sede de ese deporte. La Alberca y el Gimnasio Olímpicos fueron ubicados justamente donde están porque -según testimonios- el terreno 
Cuadro 4. Vialidades construidas o adecuadas en la ciudad de México con motivo de la Olimpiada

Vialidad

Rama sureste del Periférico

Obras viales en el Palacio de los

Deportes y el Velódromo

Viaducto Tlalpan

Liga de Av. San Jerónimo y

estacionamiento de $\mathrm{CU}$

Ampliación de Insurgentes Sur

Calle Cerro del Agua

Liga del Periférico con la Unidad

Deportiva Xochimilco

Av. Pedregal

Calzada Acoxpa
Costo

80173269

12573739

49622644

7600568

37058632

4958540

16613389

3895500

15812452

Fuente: De Pedro Ramírez Vázquez al alcalde de Munich, 9 de abril de 1969 en Acojo, caja 402, exp. 255; México 68, Mapa turístico, sop/Comité Organizador/Departamento de Turismo/PemEx. Además Gran, s. a.

era propiedad del gobierno de la ciudad, lo cual ahorraría tiempo y dinero a los organizadores. Si se mira el plano respectivo, este complejo se sustrae tanto del arco que caracteriza a la primera zona, como de la zona organizada alrededor del Palacio de los Deportes que identifica a la segunda.

\section{CONCLUSIONES}

He querido discutir en este artículo sólo dos de los problemas asociados a una historia de los juegos olímpicos de la ciudad de México. He presentado datos y explicaciones sobre la creación de un discurso y una imagen olímpicos, y el papel en estos afanes de Pedro Ramírez Vázquez. La aportación de este hombre y de su equipo representa -habría que decirlo- un mo- mento mayor en la evolución de la imagen (y autoimagen) de la cultura mexicana moderna. La olimpiada cultural y la concepción de una idea plástica, gráfica y publicitaria de los juegos buscaron menos exaltar los logros y avances del México moderno, y buscaron más reconocer, simplemente, que México estaba en el mundo, y que el mundo podía estar en México. Esa moderación es notable, y ofreció una alternativa histórica a la obsesión nacionalista (y neurótica) de convencer a los otros. La idea olímpica mexicana quiso ser más ecuménica que nacionalista, más relajada y lúdica que afirmativa.

He descrito, además, las alternativas y las decisiones para colocar sobre la tierra y bajo el cielo de la ciudad de México las instalaciones olímpicas; esas alternativas y esas decisiones reconocieron casi desde el principio un límite político de los jue- 
Instalaciones olímpicas en la ciudad de México, 1968

OBRA NUEVA

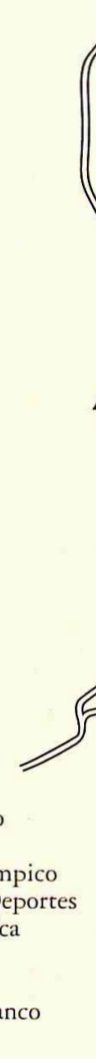

EDIFICIOS EXISTENTES

1. Auditorio Nacional

2. Arena México

3. Pista de Hielo Revolución

4. Teatro de los Insurgentes

5. Pista de Hielo Insurgentes

6. Sala de Armas

7. Campo de Hockey

8. Alberca Olímpica de Ciudad Universitaria

9. Estadio Olímpico

VIALIDADES NUEVAS

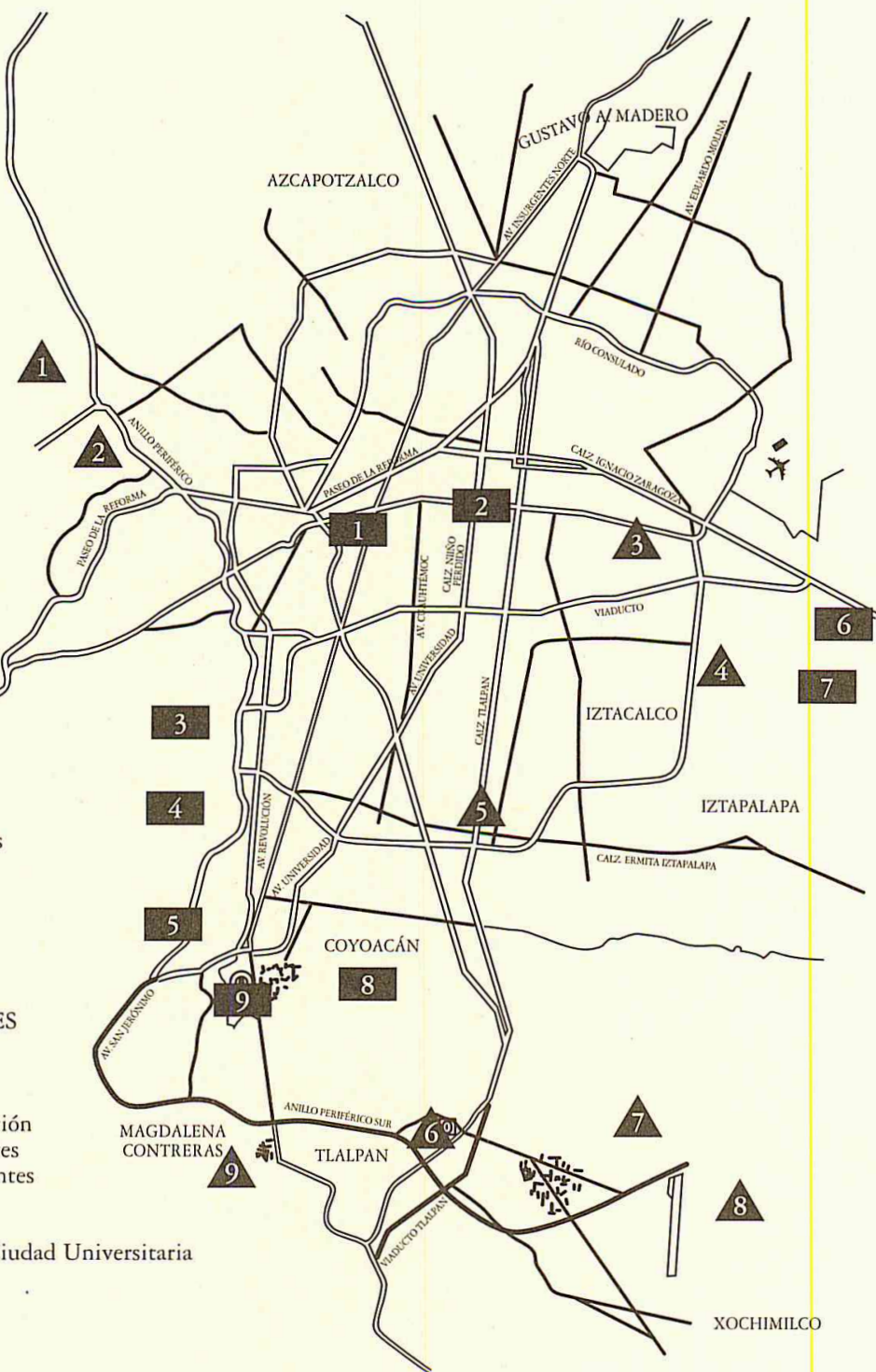

Elaboró: Consuelo Córdoba Flores. Modificó: Felipe de Jesús Calderón Flores. 
gos: éstos deberían ser baratos, más o menos coherentes con la imagen de país pobre o en todo caso que aspiraba al desarrollo o a lo que la jerga oficialista llamaba la justicia social. Ese límite, ese techo digamos, marcó la peculiar distribución espacial de los edificios olímpicos de México 68; una consecuencia: en la ciudad de México no se construyó un complejo olímpico, sino - al contrario- se optó por una relativa dispersión de las instalaciones. Pero quizá más importante aún, la organización de los juegos mexicanos no estuvo asociada a una reforma urbana en prácticamente ninguna escala. Se hizo lo que se tenía que hacer, donde se pudo.

"La memoria no es menos veleidosa que el olvido", escribió Hermann Bellinhausen. ${ }^{70} \mathrm{La}$ "foto fija" de 1968 como único recurso mnemotécnico es peligrosa, fundamentalmente porque simplifica. Los intentos y ambientes en la renovación de los discursos culturales en México, y las peculiaridades sociológicas y políticas de la ciudad de México, son dos líneas de pensamiento escasamente utilizadas en las explicaciones y narraciones de aquel año. Con esto concluyo: una cultura que pretende entrar al museo del mundo, y una ciudad en sus límites, son también una historia.

\section{ARCHIVOS}

Acojo Archivo del Comité Organizador de los Juegos Olímpicos (incorporado en el AGN)

AGN Archivo General de la Nación

DPRV Documentos de Pedro Ramírez Vázquez.

${ }^{70}$ Bellinghausen, “68”, 1988, p. 13.

\section{BIBLIOGRAFÍA}

-Aguilar Narváez, J. A., Ramírez Vázquez en el urbanismo. Conversaciones con..., Instituto Mexicano de Administración Urbana, México, 1995.

-Bachelor, Steven J., "Toiling for the "New Invaders': Autoworkers, Transnational Corporation, and Working Class Culture in Mexico City, 1955-1968" en Gilbert M. Joseph et al. (coords.), Fragments of Golden Age. The Politics of Culture in Mexico Since 1940, Duke University Press, Durham y Londres, 2001.

-Bellinghausen, Hermann, "68, modelo para armar" en Pensar el 68, Cal y Arena, México, 1988.

-Berman, Marshall, Todo lo sólido se desvanece en el aire. La experiencia de la modernidad, Siglo XXI, México, 1988.

-Camp, Roderic A., Mexican Political Biographies, 1935-1993, University of Texas, Austin, 1995.

-Canetti, Elías, "Hitler según Speer" en $L a$ conciencia de las palabras, FCE, México, 1981.

-Carr, Barry, La izquierda mexicana a través del siglo XX, trad. de Paloma Villegas, Era, México, 1996, caps. VI y VII.

-Casellas, Roberto, México 68. Confidencias de una olimpiada, Jus, México, 1992.

-Cetto, Max L., Modern Architecture in Mexico/Arquitectura moderna en México, F. A. Praeger Publisher, Nueva York, 1961.

-Clark, José de Jesús y Antonio Isse, Juegos Olimpicos de Helsinki, 1952, s. p. i., s. a. [1952]. -Connolly, Priscilla, "Introducción" en P. Connolly y Sandra Kuntz (coords.), Ferrocarriles y obras públicas, Instituto Mora/El Colegio de Michoacán/El Colegio de México/IIH-UNAm, México,1999 (Lecturas de Historia Económica Mexicana).

-Choay, Françoise, The Modern City: Planning in the 19th Century, Georg Braziller, Nueva York, 1969. 
-Davis, Diane, Urban Leviathan. Mexico City in the Twentieth Century, Temple University Press, Philadelphia, 1994.

-Díaz de Ovando, Clementina, La Ciudad Universitaria de México, t. I, Reseña bistórica 19291955, UNAM, México, 1979.

-Eco, Umberto, Los límites de la interpretación, trad. de Helena Lozano, Editorial Lumen, Barcelona, 1998.

-Enciclopedia de México, Rogelio Álvarez (director), Enciclopedia de México/Secretaría de Educación Pública, México, 1988.

-Fried, Robert C., Planning the Eternal City. Roman Politics and Planning since World War II, Yale University Press, New Haven y Londres, 1973.

-García Cortés, Adrián, La reforma urbana en México. Crónicas de la Comisión de Planificación del Distrito Federal, Bay Gráfica Ediciones, México, 1972.

-Goeritz, Mathias, "Introduction" en Hans Beacham, The Architecture of Mexico. Yesterday and Today, Architectural Book Publishing Company, Nueva York, 1969.

-Gómez Mayorga, Mauricio, ¿Qué hacer por la cindad de México? Estudio, Costa Amic, México, 1957.

—, "Tres ensayos polémicos" en Ensayos polémicos, Edamex, México, 1986.

-González Parrodi, Carlos, Memorias y olvidos de un diplomático, FCE, México, 1993.

-Gordon, Barclay F., Olympic Arcbitecture. Building for the Summer Games, John Wiley and Son, New York, 1983.

-Guttmann, Allen, The Games Must Go On. Avery Brundage and the Olympic Movement, Columbia University Press, Nueva York, 1984.

-Hargraves, John, Freedom for Catalonia? Catalan Nationalism, Spanish Identity and the Barcelona Olympic Games, Cambridge University Press, Cambridge, 2000.

-Herbert, Jean L., "Brasilia: una civilización en gestación”, Anuario de Espacios Urbanos.
Historia, Cultura, Diseño, Universidad Autónoma Metropolitana-Azcapotzalco, 1998, México.

-Herf, Jeffry, El modernismo reaccionario. Tecnología, cultura y política en Weimar y el Tercer Reich, trad. de Eduardo Suárez, FCE, Buenos Aires, 1993.

-Hernández Rodríguez, Rogelio, La formación del político mexicano. El caso de Carlos A. Madrazo, El Colegio de México, México, 1991.

-Hoberman, John, "Toward a Theory of Olympic Internationalism”, Journal of Sport History, vol. 22, núm. 1, primavera, 1995.

-Iannini, Humberto (comp.), Charlas de Pedro Ramírez Vázquez, Universidad Autónoma Metropolitana/Gernika, México, 1988.

-Koslow, Lawrence E.,"Mexican Foreign Policy Decision-making: The Mutual Adjustment of Needs and Independence", tesis doctoral, Universidad de California, Riverside, 1969.

-Krotee, March L., “An Organizational Analysis of the International Olympic Comitee" en Jeffry O. Segrave y Donald Chu (coords.), The Olympic Games in Transition, Human Kintetics Books, Champaign, 1988.

- La ciudad de México presenta su candidatura para la organización de los Juegos Olimpicos de 1960, s. p. i., 1955.

-La gran ciudad 1966-1969, s. p. i., s. a.

-Large, David C., Berlin, Basic Books, Nueva York, 2000.

-Lenskyj, Helen J., Inside the Olympic Industry. Power, Politics and Activism, State University of New York Press, Albany, 2000.

-Loaeza, Soledad, Clases medias y palítica en México. La querella escolar 1959-1963, El Colegio de México, México, 1988.

-Lorey, David E., "Postrevolutionary Context of Independence Day: The Problem of Order and Invention of Revolutionary Day, 1920s1940s" en William H. Beezley y David E. Lorey (coords.), ;Viva México! ; Viva la Independencia! Celebration of September 16, SR Books, Wilmington, 2001. 
-MacAloon, John J., This Great Symbol. Pierre de Coubertin and the Origins of the Modern Olympic Games, The University of Chicago Press, Chicago y Londres, 1981.

, "Olympic Ceremonies as a Setting for Intercultural Exchange” en Miquel de Moragas, John MacAloon y Montserrat Llines (coords.), Olympic Ceremonies. Historical Continuity and Cultural Exchange, International Olympic Commitee, Lausana, 1996.

-Mandell, Richard D., The Nazi Olympics, Macmillan, Nueva York, 1971.

-Martorell, Josep, Oriol Bohigas et al., La Villa Olimpica Barcelona 92/The Olympic Village, Gustavo Gilli, Barcelona, 1992.

-Marwik, Arthur, The Sixties, Cultural Revolution in Britain, France, Italy, and the United States, c. 1958-1974, Oxford University Press, Oxford, Nueva York, 1998.

-Medel, Vicente, "La urbanística en la olimpiada. Criterios de localización de las instalaciones olímpicas", En Concreto. Planificación, Urbanística, Arquitectura, año VII, enero-abril, 1969.

-México 68, Comité organizador de los juegos olímpicos, Miguel Galas, 4 vols., México, 1969.

-Muñoz, Fransesc, "Historic Evolution and Urban Planning Typology of Olympic Village", en línea internet http://www.blues.uab.es/ olympic.studies/viles

-Noelle, Louise, Arquitectos contemporáneos de México, Trillas, México, 1989.

—_, "Pedro Ramírez Vázquez" en Fernando González Gortázar (coord.), La arquitectura mexicana del siglo XX, CONACULTA, México, 1994.

-Pinoncelly, Salvador, Pedro Ramírez Vázquez, Conaculta, México, 2000.

-Piña Dreinhofer, Agustín, Restauración de la catedral de México. Memoria de la polémica por el arquitecto... en el tercer aniversario del incendio, Imprenta Villanueva, México, 1970.
-Quirarte, Vicente, Elogio de la calle. Biografía literaria de la ciudad de México, 1850-1992, Cal y Arena, México, 2001.

-Ramírez Vázquez en la arquitectura, unAm/Diana, México, 1989.

-Ramírez Vázquez, prefacio de Robert Auzlle, diseño de Javier Pizarro y Claudia Schrooder, García Valdés, México, 1990.

-Rivera Conde, Sergio, "El diseño en la XIX Olimpiada. Entrevista al arquitecto Pedro Ramírez Vázquez", Creación y Cultura. Revista Internacional de Arquitectura, Artes, Diseño, año 1, núm. 1, julio-agosto, 1999.

-Roche, Maurice, Mega-Events and Modernity. Olympics and Expos in the Growth of Global Culture, Routledge, Londres, 2000.

-Rodríguez Kuri, Ariel, "El otro 68: política y estilo en la organización de los juegos olímpicos de la ciudad de México", Relaciones, Revista de Historia y Sociedad, otoño, 1998.

-Rubenstein, Anne, "Bodies, Cities, Cinema: Pedro Infante Death's as Political Spectacle" en Gilbert M. Joseph et al. (coords.), Fragments of Golden Age. The Politics of Culture in Mexico Since 1940, Duke University Press, Durham y Londres, 2001.

-Sánchez Ruiz, Gerardo, La cindad de México en el periodo de las regencias, 1929-1997. Dinámica social, política estatal y producción urbano arquitectónica, Universidad Autónoma Metropolitana/Gobierno de la Ciudad de México, México, 1999.

-Scobie, Alex, Hitler's State Architecture. The Impact of Classical Antiquity, University Park, The Pennsylvania State University Press, Londres, 1990.

-Scott, James, Seeing like State. How Certain Schemes to Improve the Human Condition Have Failed, Yale University Press, New Haven, 1998.

-Seen, Alfred, Power, Politics and the Olympic Games, Human Kinetics, Chapaign, Ill., 1999. 
-Taylor, Robert R., The Word in Stone. The Role of Architecture in the National Socialist Ideology, University of California Press, Berkeley, 1974.

-Tenorio, Mauricio, Mexico at the World's Fairs. Crafting a Modern Nation, University of California Press, Berkely, 1996.

"1910 Mexico City: Space and Nation in the City of the Centenario" en William H. Beezley y David E. Lorey (coords.), ¿Viva México! ; Viva la Independencia! Celebration of September 16, SR Books, Wilmington, 2001.

-Torres Martínez, Ramón, Manuel González Rul y Carlos Ortega Viramontes, "Mesa redonda sobre el diseño arquitectónico de la Villa Olímpica”, En Concreto. Planificación, Arquitectura, Urbanística, año VII, núms. 34-35, enero-abril, 1969.

-Valenzuela, Gilberto, "Las instalaciones olímpicas mexicanas", Ingeniería, octubre, 1968.

-Villagrán García, José, "Foreword" en C. B. Smith, Builders in the Sun. Five Mexican Aribitects, Architectural Book Publishing Co., Nueva York, 1967.
-Volpi, Jorge, La imaginación y el poder. Una bistoria intelectual de 1968, Era, México, 1998.

-Ward, Peter M., México: una megaciudad. Producción y reproducción de un medio ambiente urbano, trad. de Lili Buj, CONACULTA/Alianza Editorial, México, 1991.

-Waters, Wendy C., Re-mapping the Nation: Road Building as State Formation in Post-Revolutionary Mexico, 1925-1940, UMI, Ann Arbor; 1999.

-Williams, Rosalind H., Dream Worlds: Mass Consumption in late Nineteenth-century France, University of California Press, Berkeley, 1982.

-Zarnowski, Frank, "A Look at Olympic Costs”, Citius, Altius, Fortius, núm. 1, 1992.

-Zermeño, Sergio, México: una democracia utópica, Siglo XXI Editores, México, 1978.

-Zolov, Eric, "Discovering a Land 'Mysterious and Obvious': The Renarrativizing of Postrevolucionary Mexico" en Gilbert M. Joseph et al., Fragments of Golden Age. The Politics of Culture in Mexico Since 1940, Duke University Press, Durham y Londres, 2001. 


\section{Mike Dunniong}

Doctor en Historia. Profesor asistente de Historia en la Facultad de Ciencias Sociales de la Universidad de Alaska Southeast, Ketchikan Campus.

\section{Resumen}

El tema de este artículo es la controversia acerca del expansionismo estadunidense en la posguerra de 1848. Se analizan las actitudes que prevalecían entre la población del sur de Estados Unidos hacia México en dicha coyuntura, así como los argumentos racistas que se basaban en la "ley natural" y el Destino Manifiesto, y que asignaban a los africanos el trópico como hábitat natural. Los "sureños" se valieron de estos argumentos para continuar la expansión, y con ellos justificaron la creencia de que la esclavitud debía extenderse hacia México. El trabajo se basa en fuentes periodísticas de la época poco conocidas y de difícil acceso.

Palabras clave:

Expansionismo estadunidense, relaciones México-EUA, guerra de 1846-1848, Destino Manifiesto.

\section{Abstract}

The controversy about U. S. expansionism after the 1846-1848. War is the topic of this article. It analyzes the attitudes adopted by the population of the south towards Mexico, as well as racist arguments based on so-called natural law and manifest destiny. Southerners used these arguments to continue expansion and justify the belief that slavery should be extended to Mexico. Newspaper articles are the basic source for this work.

Key words:

US-expansionism, Mexico-US relations, 1846-1848 war, Manifest Destiny.

Fecha de recepción: abril de 2002

Fecha de aceptación: agosto de 2002 